\title{
Simulating a Transition to Autonomous Mobility
}

\begin{abstract}
This study examined the transition from Traditional Vehicles (TVs) to Autonomous Vehicles (AVs) using microsimulation modelling approaches. For this purpose, the study first optimised the parameters of human driving behaviours to find out what would happen if AVs could drive with modified human behaviours. Then, the study acquired the optimised driving behaviours to evaluate how efficient AVs can be within the context of the anticipated driving behaviours. The shared road of AVs and TVs was tested for where the proportion of the AVs incremented by $10 \%$ from an entirely traditional network to a network fully occupied by AVs. Such an assessment of the shared road represented the transition periods between TVs and AVs in highway transport. Overall, the simulation results in this study indicated that AVs could substantially improve the quality of traffic, especially by reducing the number of stops, queue length, and delay time. The study also found that TVs and AVs can efficiently share their road, and the improvement in the quality of traffic increases with an increase in the proportion of AVs to TVs, up to a specific level, on the road. In this regard, according to the results from the peak and normal traffic conditions, a road with a $60 \%$ share of AVs can see its traffic quality improved as much as a road entirely populated by AVs. Therefore, dedicating $100 \%$ of the road traffic to AVs or devoting a dedicated lane for AVs in peak traffic hours might be as efficient as a shared road with $60 \%$ AVs.
\end{abstract}

\section{Introduction}

Various studies have pointed to Autonomous Vehicles (AVs) for their traffic and environmental benefits, and their possibility of providing mobility for young, old and disabled people (Bansal et al., 2016; Krueger et al., 2016; PennDOT, 2016; Fagnant and Kockelman, 2015; NHTSA, 2015; Howard and Dai, 2014; Schoettle and Sivak, 2014b, 2014c; Casley et al., 2013). Some studies have also estimated a possible timeframe in which AVs will become a reality (Litman, 2016; Kyriakidis et al. 2015; Underwood, 2014). In the one hand, it is likely that the transition and societal changes resulting from the adoption of AVs are extensive and so AVs might be required to operate and share the road with Traditional Vehicles (TVs) for some decades (Hancock et al., 2019; Laan and Sadabadi, 2017). On the other hand, there has not yet been an official adoption of AVs on highways to address the exact outcomes of their adoption for long-distance travel. Therefore, it is unclear what exactly will happen to road trips in terms of characteristics such as traffic, the environment and some others. Such characteristics impact on the transport industry, the car industry and road users. Addressing the possible outcomes of the adoption of AVs before their emergence on public roads will help different groups of experts who are dealing with the production and deployment of AVs in the road network. The related groups are including, but not limited to, transport scientists, car manufacturers, environmental protection agencies, road users, legislators, insurance companies, and all groups which might be relevant to mobility services. For this reason, the current research aimed to address whether AVs are efficient in highway transport compared to TV or not and, if so, how would the traffic flow look like during the transition period from TVs to AVs. Such an objective can be split into sub-objectives as follows:

- To identify the possible outcomes of replacing human drivers with machines on the environment, travel time, queues, delays, the level of service (LOS), and some other elements of highway trip and comparing them with those of the TVs

- To assess if AVs could be utilised in the current transport infrastructure in a shared traffic with TVs or if they would need a dedicated lane

- To evaluate the change in traffic flow during the transition period by increasing the proportion of AVs in the highway.

The evaluation of this study was conducted by modelling AVs in a hypothetical model of the M50 motorway in Dublin, Ireland. The purpose of this modelling was to attain a clear understanding of the effects of AVs on some of the characteristics of the road trip such as travel time, queue length, delay time and some others. However, since the technologies used in AVs are new, and there is no previous experience of the application of AVs in highway transport, there is no information about the driving behaviours of these vehicles. Therefore, 
this study optimised the parameters of human driving behaviours to find out what would happen if AVs could drive with modified human behaviours. The optimisation, along with a few model configurations for AVs, was conducted over 86 simulation scenarios using the microsimulation software Vissim (PTV, 2017). In recent years the approach of simulating AV networks has been widely used (Gora et al. 2020). Then, the study acquired the optimised driving behaviours to evaluate how efficient AVs can be within the context of the anticipated driving behaviours. The modelling of TVs and AVs in this study was conducted over 180 simulation scenarios under various traffic conditions of the year 2017 to ensure the results are internally consistent. Then, the shared road of TVs and AVs was tested under 11 scenarios for each peak, normal and off-peak traffic conditions where the proportion of AVs increased by $10 \%$ from an entirely traditional network to a network fully occupied by AVs. In total, the simulation for the shared road was conducted over 33 scenarios for all traffic conditions. Finally, the study adopted driving behaviours suggested by PTV in 2018 for the simulation of AVs over 41 scenarios; and compared them with those [results] of this study. The comparison of results from the simulation of the AVs of this study and those of PTV showed the extent to which the optimised driving behaviours of this study was in line with those of PTV, and validated the optimisation and simulation of this study.

It is worth noting that NHTSA (2019) and SAE (2016) have defined five levels of autonomy ${ }^{1}$, but it is hard to make a concrete statement regarding how exactly will AVs behave at each of those levels until AVs are in operation in real driving situations. Therefore, the authors cannot correspond the AVs of this study to a specific level of autonomy, but they believe that a conditional level [3] of autonomy could be replicated using their model in corporation with new technologies such as Automated Driving Systems (ADS). According to NHTSA (2019) and SAE (2016), the level 3 AVs are expected to perform all aspects of the driving tasks under some circumstances, while the presence of a driver would be necessary.

\section{Literature Review}

The advent of new sensor technologies, especially AVs in transport science and the car industry has made the microsimulation models a fundamental principle of traffic studies since the field implementation is expensive or impossible to conduct (Park and Qi, 2005). Teixeira et al. (2020) introduced a simulation framework that combines various multi-agent system simulators for a more realistic testing of the lane-merging and platooning scenarios. Such a simulation framework showed to be very helpful in better evaluation of the vehiclecoordination mechanisms and their constraints such as the vehicle to infrastructure and other road elements communications (V2X). Also, Liu et al. (2019) designed a cooperative scheduling mechanism using V2X communications for reducing AVs' delay and their average evacuation time in intersections without traffic lights, which also helps increasing safety. Liu et al. (2019) used vehicles' trajectories and intersections data in an algorithm to find the trajectories with minimum delays and smaller risk of collisions. Adopting such a mechanism resulted in $20 \%$ increase in throughput and $10 \%$ reduction in intersection delay compared to a traditional intersections with traffic lights. In addition, Dimitrakopoulos et al. (2019) introduced a modelling approach to increase the efficiency of the vehicular communications for AVs' safety management. Dimitrakopoulos et al. (2019) designed a software - which could be embedded in the vehicle - that collects data from various sources and process them using the contextual data, and previous knowledge and experiences. Such a system can help increasing safety by providing information to the AV driver about the vehicle, the road side elements, and the probable upcoming incidents or emergencies. However, the studies mentioned above argues the future steps of the adoption of AVs such as connecting AVs to communicate with each other, reducing their delay in intersections, increasing throughput and safety, while as previously mentioned, there is still a lack of information about the driving behaviours of AVs to date, nor is it clear what specific types of driving behaviours AVs will adopt in order to simulate them in the first instance. Hawkins (2018) states that Artificial Intelligence (AI) tools such as machine learning methods are being used by Google's AV (WAYMO) to train driving behaviours to the vehicles. However, Bartolini et al. (2017) specify some major obstacles in adopting AI techniques such as the connection between the defined input parameters and the output driving behaviours from machine learning. The lack of such a stable connection raises concerns for back-tracking to the exact reasons for possible errors in driving behaviours. Therefore, the current study proposes a method for optimising human driving behaviours which can be used to simulate AVs and their mixed traffic with TVs under a flexible simulation framework that could also be adoptable in other potential

\footnotetext{
${ }^{1}$ Level 0: No Automation, L1: Driver Assistance, L2: Partial Automation, L3: Conditional Automation, L4: High Automation, and L5: Full Automation. See NHTSA (2019) and SAE (2016) for the definition of each level.
} 
AV-simulation studies; this is the main contribution of this study. This study uses the traditional human driving behaviours defined in Wiedemann-99 (W99) ${ }^{1}$ to find out how efficiently AVs might behave if they drive with optimised human driving behaviours. The advantage of applying W99 is that the input parameters of the model are available and could be used for back-tracking and modification of the false driving behaviours. This demonstrates the importance of understanding the literature on past experiments which applied microsimulation methods to optimise W99 for their studies.

Lu et al. (2016) calibrated car following model parameters of Vissim using video-based processing approach. For this, they processed the traffic videos and extracted the vehicle trajectories in the form of a time-series position. Then, they calculated the optimal value of the car following parameters using a golden section search algorithm and minimised the errors between the observed and simulation results in Vissim. Also, Chu et al. (2003) calibrated the car following parameters of Paramics for freeway traffic with consideration of the route choice model and estimation of the origin-destination pairs. For this, Chu et al. (2003) used sensitivity analysis and adopted a mathematical method referred to as parameter fine-tuning method and GEH statistics to minimise the deviation between the observed data and simulation results in Paramics. Table 1 represents a list of studies with a focus on the adoption of W99 and their acquired methods of assessment. Additionally, in light of the subject of this study, Zeidler et al. (2019) and PTV (2017) stated that W99 could also be adopted to replicate autonomous behaviours and Virdi et al. (2019) incorporated W99 in their simulation model to assess the safety of Connected AVs (CAVs).

In general, with regard to the findings of the studies in this area, specially the studies that adopted sensitivity analysis for the calibration of W99, it can be seen that W99 is a driving behaviour model that is sensitive to its parameters and malleable enough to be tuned for a conditional level of automation.

Table 1. Summary of studies with an emphasis on the evaluation of W99

\begin{tabular}{|c|c|c|c|c|c|}
\hline Study & Year & Location & Study Type & Assessment Method & $\begin{array}{l}\text { Evaluation } \\
\text { Tool }\end{array}$ \\
\hline Calvert et al & 2020 & $\begin{array}{l}\text { The } \\
\text { Netherland }\end{array}$ & $\begin{array}{l}\text { Urban } \\
\text { Network }\end{array}$ & $\begin{array}{l}\text { Calibration of Vissim W99 } \\
\text { parameters using trial data }\end{array}$ & Vissim \\
\hline Virdi et al. & 2019 & Australia & $\begin{array}{l}\text { Urban } \\
\text { Network and } \\
\text { Freeway }\end{array}$ & $\begin{array}{l}\text { Surrogate Safety Assessment } \\
\text { Module (SSAM) }\end{array}$ & Vissim \\
\hline Lu et al. & 2016 & Canada & $\begin{array}{l}\text { Urban } \\
\text { Network }\end{array}$ & $\begin{array}{l}\text { Video processing with sensitivity } \\
\text { analysis }\end{array}$ & Vissim \\
\hline Durrani et al. & 2016 & US & Freeway & Analysing vehicle trajectories & Vissim \\
\hline Song et al. & 2015 & China & Freeway & $\begin{array}{l}\text { Numerical analysis of vehicle } \\
\text { trajectories }\end{array}$ & Matlab \\
\hline Essa & 2015 & Canada & $\begin{array}{l}\text { Urban } \\
\text { Network }\end{array}$ & $\begin{array}{l}\text { Sensitivity Analysis and genetic } \\
\text { algorithm }\end{array}$ & $\begin{array}{l}\text { Vissim and } \\
\text { Paramics }\end{array}$ \\
\hline Ge and Menendez & 2014 & Switzerland & $\begin{array}{l}\text { Urban } \\
\text { Network }\end{array}$ & Sensitivity analysis & $\begin{array}{l}\text { Aimsun and } \\
\text { Vissim }\end{array}$ \\
\hline Aghabayk et al. & 2013 & Australia & Freeway & Evolutionary algorithms & Vissim \\
\hline Menneni et al. & 2008 & US & Freeway & Genetic algorithm & Vissim \\
\hline $\begin{array}{l}\text { Park and } \\
\text { Schneeberger }\end{array}$ & 2003 & US & Freeway & Sensitivity analysis & Vissim \\
\hline Chu et al. & 2003 & US & Freeway & Sensitivity analysis & Paramics \\
\hline Ma and Abdullhai & 2002 & Canada & $\begin{array}{l}\text { Urban } \\
\text { Network }\end{array}$ & Genetic algorithm & Paramics \\
\hline Gardes et al. & 2002 & US & Freeway & Sensitivity analysis & Paramics \\
\hline
\end{tabular}

\footnotetext{
${ }^{1}$ A car-following model that is known for its extensive use in microsimulation software Vissim (Higgs et al., 2011)
} 
Furthermore, some studies focused on the simulation of AVs and CAVs. For example, Bischoff and Maciejewski (2016) proposed a simulation model to assess the replacement of TVs with autonomous taxis in Berlin. They applied an algorithm to dispatch autonomous taxies to handle the demand for vehicles in the network. The results of their simulation showed that one autonomous taxi could provide the demand served by ten TVs. Also, Talebpour and Mahmassani (2016) presented a framework to simulate different car following models using stability analysis of traffic stream behaviour for different penetration rates of AVs. The results of their study revealed that AVs could be useful in preventing shockwave formation and propagation of traffic flow and improving the string stability of shared traffic streams. Besides, road throughput showed a substantial potential to increase in some scenarios, where automation was incorporated. Furthermore, Yea and Yamamoto (2018) developed a two-lane traffic flow model for the simulation of CAVs and measured their impact on road capacity. The results of their study indicated that road capacity increases with an increase in the penetration of CAVs. Also, Zhu and Ukkusuri (2018) adopted a cell-based simulation approach for modelling the proactive driving behaviours of connected vehicles. Their model identifies the trajectory of connected cars and simulates proactive driving behaviours by adjusting the exit flow of the model cells containing connected vehicles. The results of their simulation verify that the presence of connected vehicles on the network substantially impact on the smoothness of traffic flow and help reduce emissions. Moreover, Virdi et al. (2019), investigated the safety impacts of the shared fleets of TVs and CAVs. They incorporated a CAV control algorithm and Surrogate Safety Assessment Module (SSAM) with Vissim to assess the safety of CAVs in various penetration from a traditional road network to a network fully occupied by CAVs. The results of their study showed some disbenefit of adopting CAVs in low penetrations (like 20\%), whereas a high penetration rate (like 90\%) has significantly reduced the conflicts at junctions, which substantially help increase safety.

further explore these issues using a SSAM approach and find that this approach could be used in AVs to find
dangerous road users and produce manoeuvres for other road users to avoid possible accidents. Table 1 reviews studies with a focus on the simulation of AVs and CAVs and the acquired methods.

Table 1. Summary of studies with a focus on the simulation of AVs

\begin{tabular}{|c|c|c|c|c|c|}
\hline Study & Year & Location & Study Type & Assessment Method & Evaluation Tool \\
\hline Rafael et al. & & Portugal & Urban Network & $\begin{array}{l}\text { Vehicle Specific Power }- \\
\text { emissions estimation }\end{array}$ & Vissim \\
\hline Bhargava et al & 2020 & & Freeway/tunnel & Simulation vs real world data & Vissim \\
\hline Tomás et al. & & Portuga & Freeway & $\begin{array}{l}\text { Vehicle Specific Power - } \\
\text { emissions estimation }\end{array}$ & Vissim \\
\hline Zheng et al. & 870 & China & & Geometric Analysis & Vissim \\
\hline Katrakazas et al. & 201 & $\begin{array}{l}\text { United } \\
\text { Kingdom }\end{array}$ & Freeway & $\begin{array}{l}\text { Dynamic Bayesian Network } \\
\text { model \& Surrogate Safety } \\
\text { Assessment Module }\end{array}$ & Vissim \\
\hline Virdi et al. & 2019 & Australia & $\begin{array}{l}\text { Urban Network } \\
\text { and Freeway }\end{array}$ & $\begin{array}{l}\text { Surrogate Safety Assessment } \\
\text { Module }\end{array}$ & $\begin{array}{l}\text { Vissim and Virdi } \\
\text { CAV Control } \\
\text { Protocol (VCCP) } \\
\text { algorithm } \\
\end{array}$ \\
\hline Alam and Habib & 2018 & Canada & Urban Network & $\begin{array}{l}\text { Latin Hypercube Sampling } \\
\text { technique }\end{array}$ & Vissim \\
\hline $\begin{array}{l}\text { Yea and } \\
\text { Yamamoto }\end{array}$ & 2017 & $\overline{\mathrm{US}}$ & Freeway & Cellular automation & $\begin{array}{l}\text { Mathematical } \\
\text { modelling and } \\
\text { NGSIM }\end{array}$ \\
\hline $\begin{array}{l}\text { Zhu and } \\
\text { Ukkusuri }\end{array}$ & 2017 & US & Urban Network & $\begin{array}{l}\text { Mesoscopic cell transmission } \\
\text { model; vehicle trajectory data }\end{array}$ & Matlab \\
\hline $\begin{array}{l}\text { Laan and } \\
\text { Sadabadi }\end{array}$ & 2017 & US & Freeway & $\begin{array}{l}\text { Simultaneous perturbation } \\
\text { stochastic approximation } \\
\text { algorithm }\end{array}$ & $\begin{array}{l}\text { Corridor Macro } \\
\text { Simulation } \\
\text { Software } \\
\text { (CORMAK), } \\
\text { developed in JAVA }\end{array}$ \\
\hline $\begin{array}{l}\text { Talebpour and } \\
\text { Mahmassani }\end{array}$ & 2016 & US & Urban Network & String stability analysis and SA & $\begin{array}{l}\text { Mathematical } \\
\text { modelling }\end{array}$ \\
\hline Gerado et al. & 2015 & Mexico & Urban Network & $\begin{array}{l}\text { Proposed parameter estimator } \\
\text { algorithm }\end{array}$ & $\begin{array}{l}\text { Mathematical } \\
\text { modelling }\end{array}$ \\
\hline
\end{tabular}


As discussed in Section 2, some recent studies have calibrated driving behaviours for the analysis of traffic flow, vehicle trajectory, road capacity, and road safety. However, more research and analysis in this context would be helpful to assess a broader range of the impacts of AVs on highway transport. In this context, the experiment in the current research also provides a set of optimised driving behaviours, which could be used for the simulation of AVs in this study and any simulation software in future studies. Then, the study acquired the optimised driving behaviours to evaluate how efficient AVs can be within the context of the anticipated driving behaviours and used them for the evaluation of AVs during the transition period from TVs to AVs. In general, this research has contributed the following findings to the state of knowledge in the field of AVs:

- Proposing a method for optimising human driving behaviours using sensitivity analysis. This study optimised the driving behaviours of W99 using sensitivity analysis for the modelling of AVs along with some model configurations for AVs. The results of simulations with optimised W99 provided a vision of what might happen if AVs can drive with optimised human driving behaviours and the extent to which they can improve the quality of trip characteristics.

- Addressing the impact of each parameters of W99 on travel time, queue length, delays, fuel consumption, emissions, and LOS. As part of the optimisation process, the study estimated how these characteristics are affected by changes in the W99 parameters. The results of this evaluation provided a useful guideline on how much the W99 parameters must change to attain the desired improvements in travel time, queues, delays, and the other assessed parameters.

- Examining the efficiency of AVs on long trips. For this purpose, a 40-km motorway was modelled on Vissim. The simulation comprised 180 scenarios for a diverse range of traffic conditions, which is unprecedented and provides a profound understanding of what would happen to traffic flow over long travel distances. The results of the simulation were assessed for travel time, queue length, delays, LOS, road throughput, fuel consumption, and emissions.

- Examining the operability of TVs and AVs in shared road traffic. TVs and AVs were designed to work in separate modes and then in shared traffic situations with different proportions on the road. For this purpose, the share of AVs incremented by $10 \%$ in each scenario from entirely regular traffic flow to a network operating fully with AVs. The results showed how flexibly TVs and AVs can interact with each other and what share of AVs is needed on a motorway to cause considerable reductions in queues, delays, fuel consumption, and emissions along with increases in the network throughput and an improvement in LOS.

- Adopting Cronbach's Alpha reliability test in highway traffic simulation model. To the best of the author's knowledge, Cronbach's Alpha has not been used before for assessing the internal consistency of the highway traffic simulation models. Hence, due to the high performance, ease of use, and availability of this reliability test in the statistical software IBM SPSS, Cronbach's Alpha method was adopted as a model reliability test in this paper. The evaluation of results in this regard revealed that Cronbach's Alpha could be adopted as a reliable and efficient tool for investigating the reliability of the traffic simulation models.

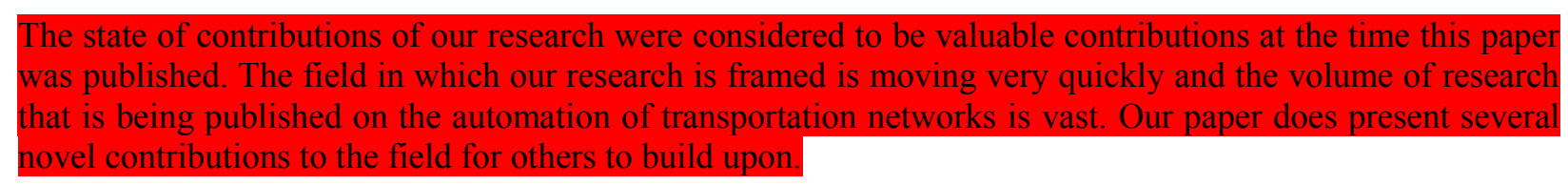

\section{Methods}

\subsection{Microsimulation Software}

Multiple studies such as Ronaldo (2012), Gao (2008), Byungkyu et al. (2006), and Jones et al. (2004) evaluated various micro-simulation software packages adopted for transportation and traffic simulations. In this context, Saidallah et al. (2016) conducted one of the most comprehensive assessments of the various simulation software packages. Saidallah et al. (2016) studied 11 software packages based on eight criteria such as the simulation type (microscopic, mesoscopic, and macroscopic), visualisation (2D, 3D), software's capability for designing infrastructure, and some others (as shown in Table 3). Regarding the efficiency of the chosen software packages for the simulation in this study, a weighting method was proposed by the current study that helped to find which software package can ideally provide the needs of this study. The weighting of software packages was conducted using the results obtained from the study conducted by Saidallah et al. (2016). The 
results of the weighting assessment showed that Vissim provides the required features for designing TVs and AVs, and it is an available software for the simulation in this study. Therefore, Vissim seemed the most competent software package for the simulations of the current study; hence, it was adopted for the simulation of TVs and AVs in this study.

Table 3. Evaluation of the simulation software packages ${ }^{1}$

\begin{tabular}{|c|c|c|c|c|c|c|c|c|}
\hline \multirow{2}{*}{\multicolumn{2}{|c|}{ Feature }} & \multirow{2}{*}{\multicolumn{2}{|c|}{ Weight }} & \multicolumn{5}{|c|}{ Simulation Software } \\
\hline & & & & \multirow{3}{*}{$\begin{array}{c}\text { Aimsun } \\
0\end{array}$} & \multirow{3}{*}{$\begin{array}{c}\text { Corsim } \\
0\end{array}$} & \multirow{3}{*}{$\begin{array}{c}\text { Paramics } \\
0\end{array}$} & \multirow{3}{*}{$\begin{array}{c}\text { Sumo } \\
1\end{array}$} & \multirow{3}{*}{$\begin{array}{c}\text { Vissim } \\
0\end{array}$} \\
\hline \multirow{4}{*}{$\begin{array}{l}\text { Availability of } \\
\text { the simulator }\end{array}$} & Open-source, and & Yes & $1 *$ & & & & & \\
\hline & available & No & $0 * *$ & & & & & \\
\hline & Commercial & $\begin{array}{c}\text { Not } \\
\text { Available }\end{array}$ & $-1 * * *$ & -1 & -1 & -1 & 1 & 1 \\
\hline & & Available & 1 & & & & & \\
\hline \multirow{4}{*}{\multicolumn{2}{|c|}{ Visualisation mode }} & & 1 & & & & & \\
\hline & & $2 \mathrm{D}$ & 0 & 1 & 1 & 1 & 1 & 1 \\
\hline & & $3 \mathrm{D}$ & 1 & 1 & 1 & 1 & 0 & 1 \\
\hline & & & 0 & & & & & \\
\hline \multirow{6}{*}{$\begin{array}{l}\text { Infrastructure } \\
\text { design }\end{array}$} & \multirow{3}{*}{$\begin{array}{l}\text { Difficulty in } \\
\text { designing } \\
\text { (intersection, } \\
\text { roundabout, etc.) }\end{array}$} & Easy & 1 & & & & & \\
\hline & & Medium & 0 & 1 & 0 & 1 & -1 & 1 \\
\hline & & Difficult & -1 & & & & & \\
\hline & \multirow{3}{*}{$\begin{array}{l}\text { Flexibility in } \\
\text { designing various } \\
\text { road types (freeway, } \\
\text { urban, etc.) }\end{array}$} & Flexible & 1 & & & & & \\
\hline & & Limited & 0 & 1 & -1 & 1 & -1 & 1 \\
\hline & & $\begin{array}{c}\text { Very } \\
\text { Limited }\end{array}$ & -1 & & & & & \\
\hline \multirow{6}{*}{$\begin{array}{l}\text { Micro features } \\
\text { for creating } \\
\text { vehicles }\end{array}$} & \multirow{2}{*}{$\begin{array}{l}\text { Defining new } \\
\text { vehicle types }\end{array}$} & Yes & 1 & \multirow{2}{*}{1} & \multirow{2}{*}{0} & \multirow{2}{*}{0} & \multirow{2}{*}{0} & \multirow{2}{*}{1} \\
\hline & & No & 0 & & & & & \\
\hline & \multirow{2}{*}{$\begin{array}{l}\text { Defining vehicle } \\
\text { dimensions }\end{array}$} & Yes & 1 & \multirow{2}{*}{1} & \multirow{2}{*}{0} & \multirow{2}{*}{0} & \multirow{2}{*}{0} & \multirow{2}{*}{1} \\
\hline & & No & 0 & & & & & \\
\hline & \multirow{2}{*}{$\begin{array}{l}\text { Adopting/Flexibility } \\
\text { in modifying W99 }\end{array}$} & Yes & 1 & \multirow{2}{*}{0} & \multirow{2}{*}{0} & \multirow{2}{*}{0} & \multirow{2}{*}{0} & \multirow{2}{*}{1} \\
\hline & & No & 0 & & & & & \\
\hline \multicolumn{2}{|l|}{ Overall value } & & 9 & 5 & 0 & 3 & 1 & 8 \\
\hline
\end{tabular}

Note: the weighting values could be anything other than $-1,0$, and 1 as long as they provide a fair distinction regarding the advantage and disadvantages of a software feature based on the requirements and goals of a research.

* 1: Representing an advantage regarding the adoption of the related software in this research

** 2: Representing a neutral impact regarding the adoption of the related software in this research

*** 3: Representing a disadvantage regarding the adoption of the related software in this research

\subsection{Vissim Model}

In order to evaluate the efficiency of AVs in motorway traffic flow, they are designed in a conceptual model of the M50 motorway which is shown in Figure 1. The reason for choosing M50 was that it is the busiest motorway in Ireland. Besides, M50 has substantial importance in controlling the traffic of the national routes radiating from Dublin, as they begin at their junctions with the M50 (Irish Times, 2017). The simulation was firstly conducted for TVs using Vissim with traffic data extracted from the Transport Infrastructure Ireland (TII) traffic data site (TII, 2017). Then the model was designed to simulate AVs using the same traffic data and road network. The model evaluates travel scenarios generated from Bray to Dublin Airport, including traffic from six merging roads (junctions), which are referred to as nodes hereafter.

\footnotetext{
1 *The simulation model 'Features' in this Table are extracted from the studies conducted by Saidallah et al. (2016). The current study added a weighting evaluation to this Table based on its needs and limitations. All rights regarding the defined features in Table 3 reserved to the authors of the study 'Saidallah et al. (2016)'.
} 


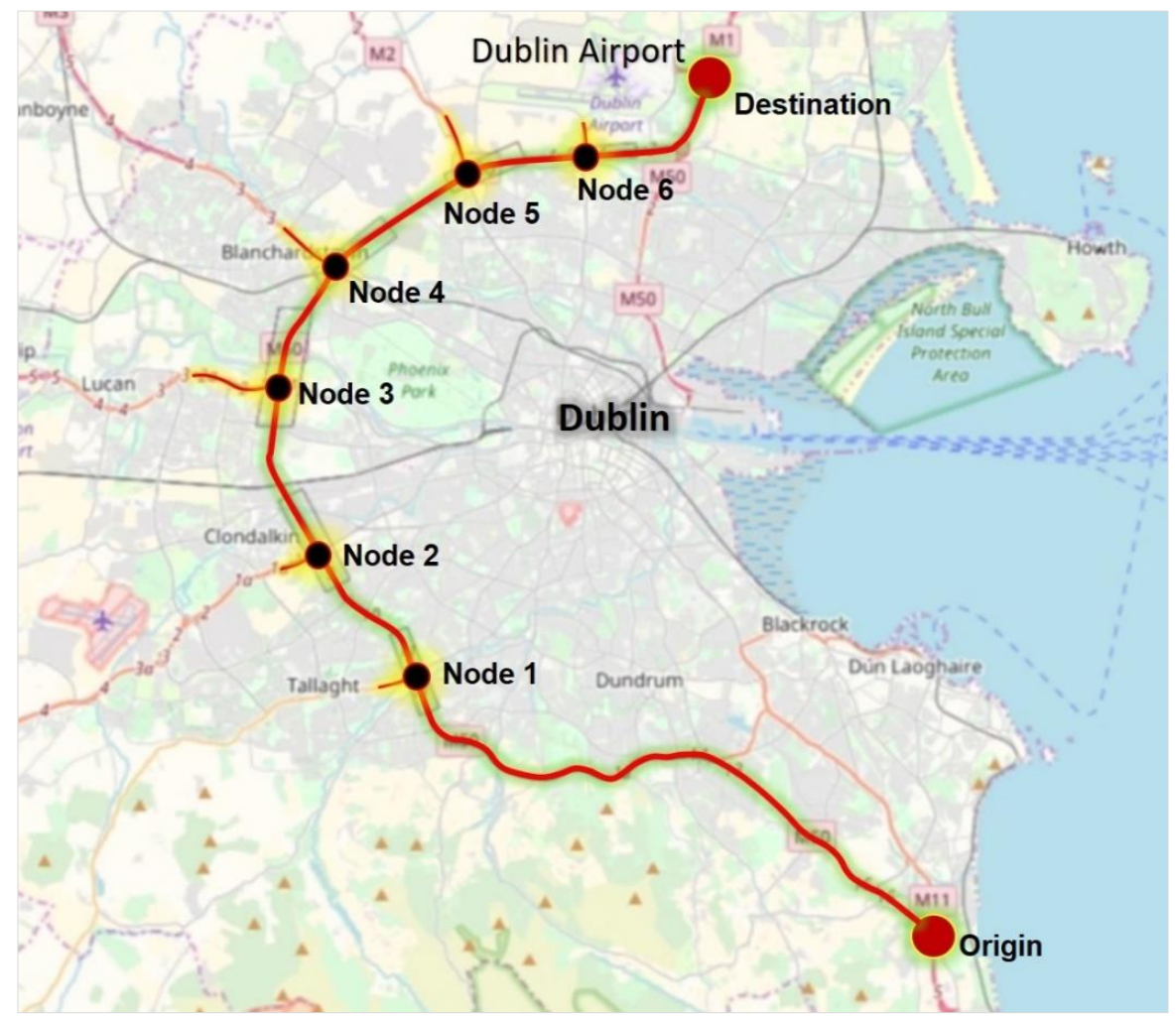

Figure 1. Simulation network area

As with all modelling tasks, some assumptions are made for the Vissim model in this study, as follow:

- The Vissim model is a conceptual model of the M50 motorway. Therefore, the results do not represent the exact traffic stream of the M50 but describe a conceptual situation to compare the performance of TVs and AVs. However, all efforts were made to make the model as realistic as possible.

- The motorway has four lanes (in one direction) across its entire length. The number of lanes in some sections of the M50 varies between 3 to 4 . So, the study decided to model a 4-lane motorway across its entire length to reduce the number of Vissim network connectors which would help reduce the probable model errors at connector locations.

- The M50 has six nodes in total. Such an assumption was considered since there was a lack of sufficient traffic data for minor junctions at M50.

- Half of the traffic from the approaching roads to the M50 nodes (for example, N7) is heading towards the airport. This assumption was made since there is no information about the percentage of traffic approaching the M50 that travels north, south or into the city. In this context, contact was made with TII to retrieve the exact traffic data for all junctions and their turning ratios. TII confirmed that they do not have those turning proportions from the traffic count data, as they do not capture all movements entering and leaving the interchange (Kennan, D, \& Brennan, D., personal communication, Feb 12, 2019). However, the N7 interchange had a counter, and that provided some information about the traffic inside the junction. In this context, the peak traffic volume for N7 according to the data sent by TII was $2,103 \mathrm{veh} / \mathrm{h}$ for the traffic towards the airport, which was so close to the assumption of this study $(2,093$ $\mathrm{veh} / \mathrm{h})$. Therefore, the assumption for cutting the total approaching traffic in half seemed acceptable for the modelling of this study.

- All cars on the M50 move towards the airport and none leave the M50. This assumption was made for a better evaluation of the travel time, the number of vehicles, and vehicle delay in a long motorway trip between two destinations where no vehicles leave the trip.

Generally, when a simulation model aims to assess the changes in a real network, it needs comprehensive calibration to ensure that the model is representative of the reality and the quality of the results is maximised for the experimental data (Trucano et al., 2006). In this context, the calibration refers to the adjustments of the simulation parameters to conform to the real model of the road so that the simulation model can represent 
realistic results (as much as possible) that comply with that of the actual condition. However, the purpose of the simulation in this study is to compare the efficiency of AVs with that of TVs in motorway transport and not to address the exact consequences of using AVs on the M50. So, as long as the model and traffic data are the same for both TVs and AVs, they can be compared. In light of this, the model for this study is a conceptual model of the M50, not an exact model. Besides, as explained in the assumptions, detailed information about the turning ratios at nodes was not available. Therefore, a comprehensive calibration of the model was not possible since the study had to make some assumptions about the traffic data and turning ratios at the nodes However, some configurations were applied to the Vissim model for AVs based on the assumption that AVs will offer improvements compared to human behaviours. The following points present the model configurations used to demonstrate certain autonomous behaviours. Such settings will work in parallel with the optimised driving behaviours for the current study, which will be discussed later in Section 3.4.

- The average speed limit of the M50 motorway is $100 \mathrm{~km} / \mathrm{h}$, which is applied to the simulation model of this study. It is worth noting that Vissim applies a speed range of $80 \mathrm{~km} / \mathrm{h}-120 \mathrm{~km} / \mathrm{h}$ for an ordinary speed of $100 \mathrm{~km} / \mathrm{h}(\mathrm{PTV}, 2017)$. Such a speed distribution provides more realistic traffic flow of the vehicles in the model. Therefore, for the modelling in this study, the $100 \mathrm{~km} / \mathrm{h}$ speed of TVs is distributed in the range of $80-120 \mathrm{~km} / \mathrm{h}$ to provide for the possibility of driving at any rate in this range similar to what Vissim does for such speed. Also, PTV (2017) recommends removing the speed distribution of vehicles for AVs as these vehicles are expected to drive without such a variation of speed. Therefore, for the modelling of AVs in this study - with respect to the average speed of the cars on the M50 - AVs are limited to driving at $100 \mathrm{~km} / \mathrm{h}$ without distribution of their speed. It is worth noting that AVs of this study can reduce their speed when there is an object or vehicle in front of them, but they drive at a constant speed and never exceed the speed limit of $100 \mathrm{~km} / \mathrm{h}$.

- According to PTV (2017), a traditional car can have a maximum acceleration of $3.5 \mathrm{~m} / \mathrm{s}^{2}$, which occurs at the speed of $0 \mathrm{~km} / \mathrm{h}$. The acceleration reduces with the increase in speed, reaching $0 \mathrm{~m} / \mathrm{s}^{2}$ at the speed of $250 \mathrm{~km} / \mathrm{h}$. In this regard, and based on what has already been explained about the speed of the cars in the model of this study, a TV can drive at any speed in the range of $80-120 \mathrm{~km} / \mathrm{h}$ and the acceleration changes accordingly in the range of $0.42-2.29 \mathrm{~m} / \mathrm{s}^{2}$ (PTV, 2017). However, an AV can only drive at 100 $\mathrm{km} / \mathrm{h}$ without distribution of speed. Therefore, there will be no distribution in the desired acceleration of AVs; thus, a constant desired acceleration of $1.04 \mathrm{~m} / \mathrm{s}^{2}$ (as of TVs in such speed) is applied to AVs. Such an acceleration could be considered too conservative, but due to a lack of official report about AVs' acceleration and deceleration, this study avoided to make broad assumptions in this regard, to replicate a safer driving operation of AVs.

- PTV (2017) adopts a fixed desired deceleration for TVs at all speeds. In this context, the AVs of this study are defined with the mean desired deceleration of AVs, but without a distribution. Also, PTV (2017) defines a distribution of speed and deceleration for TVs, while AVs are defined without such distributions in maximum deceleration.

- Human drivers experience distractions such as feeling drowsy which may lead to them closing their eyes for a few seconds. They also may lose control due to alcohol usage, using mobile phones or a combined effect of such distractions (Fagnant and Kockelman, 2015). A report from NHTSA (2018) states that reading a text message would distract a driver for about 5 seconds on average. However, AVs will not have any such distractions since AVs will adopt smart sensors and cameras such as LIDAR for navigation. In light of this, there is a driving behaviour in Vissim called "temporary lack of attention" to replicate such human distractions. For the simulation in this study, a distraction time of 5 seconds was built in for $\mathrm{TVs}$, occurring for $5 \%$ of the total length of the driving period, while this value was considered zero for AVs.

The application of such model configurations on speed, acceleration and deceleration for AVs means that they can run more smoothly in terms of acceleration and braking operations. Consequently, AVs might be able to offer continuous traffic flow with a nearly constant velocity, which might also increase the road capacity and reduce congestion. In addition to the model settings explained in this Section, an optimisation of W99 was conducted and applied to the driving behaviours of AVs.

The traffic data was acquired from TII (2017), which is the database of traffic data in Ireland. Traffic data was assessed for all nodes of Figure 1, along with information on all the traffic originating from Bray for the whole data year 2017. The data was extracted from the related data points on the TII data site, then the cumulative volume for each month was calculated to find months with peak, normal and off-peak traffic conditions. Table 4 shows the traffic volume $(\mathrm{Veh} / \mathrm{h})$ at each data point for each month of the year 2017. 
According to TII (2017) May, September and February experienced peak, normal, and off-peak traffic conditions, respectively. Therefore, these months were selected for further analysis and simulation. In this context, the traffic data were analysed in greater detail to find the peak, normal, and off-peak traffic conditions within each of these three months. Such an assessment covered a diverse range of traffic conditions with the minimum, average and maximum traffic conditions for the whole year included in the evaluation. Table 5 demonstrates total traffic volume for 10 peak, normal, and off-peak within each of the selected months.

Table 4. Traffic volume (Veh/h) at each data point for each month of the year 2017 (TII, 2017)

\begin{tabular}{ccccccccc}
\hline \multirow{2}{*}{ Month } & Origin & Node 1 & Node 2 & Node 3 & Node 4 & Node 5 & Node 6 & \multirow{2}{*}{ Total } \\
& Data site 1 & Data site 2 & Data site 3 & Data site 4 & Data site 5 & Data site 6 & Data site 7 & \\
\hline Jan & $1,125,968$ & 451,359 & $1,463,279$ & $1,436,308$ & $1,141,295$ & 535,563 & 234,042 & $6,387,814$ \\
Feb & $1,067,638$ & 436,842 & $1,418,848$ & $1,392,433$ & $1,105,306$ & 519,935 & 225,758 & $\mathbf{6 , 1 6 6 , 7 6 0}$ \\
Mar & $1,233,190$ & 492,986 & $1,597,094$ & $1,571,852$ & $1,244,545$ & 591,863 & 259,726 & $6,991,256$ \\
Apr & $1,201,310$ & 452,179 & $1,534,849$ & $1,498,097$ & $1,180,427$ & 546,957 & 258,334 & $6,672,153$ \\
May & $1,287,254$ & 496,855 & $1,662,277$ & $1,627,478$ & $1,286,058$ & 608,954 & 280,804 & $\mathbf{7 , 2 4 9 , 6 8 0}$ \\
Jun & $1,231,291$ & 461,010 & $1,594,936$ & $1,557,649$ & $1,233,810$ & 576,554 & 280,482 & $6,935,732$ \\
Jul & $1,289,729$ & 450,729 & $1,633,137$ & $1,585,320$ & $1,220,319$ & 575,278 & 281,388 & $7,035,900$ \\
Aug & $1,293,855$ & 450,869 & $1,657,952$ & $1,597,677$ & $1,234,272$ & 590,786 & 283,136 & $7,108,547$ \\
Sep & $1,205,815$ & 467,307 & $1,595,776$ & $1,575,862$ & $1,227,316$ & 581,786 & 277,504 & $\mathbf{6 , 9 3 1 , 3 6 6}$ \\
Oct & $1,203,539$ & 468,021 & $1,572,276$ & $1,562,638$ & $1,237,222$ & 585,991 & 270,952 & $6,900,639$ \\
Nov & $1,203,069$ & 477,573 & $1,595,394$ & $1,564,769$ & $1,217,837$ & 607,787 & 258,041 & $6,924,470$ \\
Dec & $1,126,774$ & 451,154 & $1,443,018$ & $1,475,689$ & $1,178,114$ & 525,740 & 222,935 & $6,423,424$ \\
\hline Average & $1,205,786$ & 463,074 & $1,564,070$ & $1,537,148$ & $1,208,877$ & 570,600 & 261,092 & $6,845,847$ \\
Std. Dev.* & 70,435 & 18,291 & 82,065 & 70,771 & 49,452 & 30,894 & 22,328 & 318,599 \\
CV** & $\mathbf{0 . 0 6}$ & $\mathbf{0 . 0 4}$ & $\mathbf{0 . 0 5}$ & $\mathbf{0 . 0 5}$ & $\mathbf{0 . 0 4}$ & $\mathbf{0 . 0 5}$ & $\mathbf{0 . 0 9}$ & $\mathbf{0 . 0 5}$ \\
\hline
\end{tabular}

* Standard Deviation

** Coefficient of Variation $=$ average/standard deviation

Table 5. Total traffic volume for 10 peak, normal, and off-peak traffic within each of the selected months (TII, 2017)

\begin{tabular}{|c|c|c|c|c|c|c|c|c|c|}
\hline \multirow[b]{2}{*}{$\begin{array}{l}\text { Traffic } \\
\text { condition }\end{array}$} & \multicolumn{3}{|c|}{ February } & \multicolumn{3}{|c|}{ May } & \multicolumn{3}{|c|}{ September } \\
\hline & Peak & Normal & Off-peak & Peak & Normal & Off-peak & Peak & Normal & Off-peak \\
\hline \multirow{10}{*}{$\begin{array}{l}10 \text { hourly } \\
\text { traffic within } \\
\text { each traffic } \\
\text { condition }\end{array}$} & 10,289 & 9,713 & 7,740 & 14,420 & 10,103 & 6,735 & 13,996 & 10,002 & 8,699 \\
\hline & 10,281 & 9,808 & 9,054 & 14,386 & 10,241 & 8,071 & 13,978 & 10,280 & 9,260 \\
\hline & 10,296 & 9,809 & 6,431 & 14,135 & 10,213 & 9,319 & 14,014 & 9,876 & 8,732 \\
\hline & 10,552 & 9,832 & 7,911 & 14,258 & 10,264 & 7,790 & 13,873 & 9,866 & 7,823 \\
\hline & 10,471 & 9,745 & 6,600 & 14,180 & 10,005 & 8,290 & 14,008 & 10,011 & 8,634 \\
\hline & 10,444 & 9,854 & 9,102 & 14,516 & 10,068 & 7,120 & 14,048 & 9,774 & 8,902 \\
\hline & 10,532 & 9,776 & 8,136 & 14,272 & 10,127 & 8,603 & 14,157 & 10,002 & 8,608 \\
\hline & 10,237 & 9,907 & 6,937 & 14,072 & 10,162 & 7,567 & 13,960 & 9,893 & 7,507 \\
\hline & 10,151 & 9,997 & 8,184 & 14,151 & 10,203 & 8,437 & 14,288 & 9,722 & 8,667 \\
\hline & 10,311 & 9,662 & 6,632 & 14,452 & 10,177 & 7,485 & 14,063 & 9,810 & 9,280 \\
\hline Average & 10,356 & 9,810 & 7,673 & 14,284 & 10,156 & 7,942 & 14,039 & 9,924 & 8,611 \\
\hline Std. Dev.* & 134 & 96 & 989 & 152 & 81 & 762 & 114 & 160 & 560 \\
\hline $\mathrm{CV}^{* *}$ & 0.01 & 0.01 & 0.13 & 0.01 & 0.01 & 0.10 & 0.01 & 0.02 & 0.07 \\
\hline
\end{tabular}




\subsection{Driving Behaviours}

As previously discussed in this paper, there is no experience of the application of AVs, to date, in highway transport, and there is no information about the driving behaviours of these vehicles. Therefore, the current research decided to simulate AVs by using traditional driving behaviour model of W99 (Wiedemann, 1999) to find out what would happen if AVs could drive with modified human behaviours. W99 is still being used in Vissim (PTV, 2017) and it was adopted by several studies such as Aghabayk et al. (2013), Higgs et al. (2011), and Menneni et al. (2008). Moreover, the results of studies by Virdi et al. (2019), Zeidler et al. (2019) and PTV (2017) show that W99 could be used to replicate autonomous behaviours. The W99 in Vissim relies on ten user-defined parameters ${ }^{1}$ to represent human driving behaviour in freeway traffic (PTV, 2017; Lowens and Machemehl, 2007). Several previous studies such as Lu et al. (2016); Song et al. (2015); Aghabayk et al. (2013), Higgs et al. (2011), have analysed the parameters of Wiedemann 99 in depth. Therefore, the definitions and equations for those parameters are not presented in this study, but the defined values for W99 are briefly presented in Table 9. In this study, an optimisation method was applied since the default values for driving behaviours might not represent the desired driving behaviours for AVs.

\subsection{Optimisation Using Sensitivity Analysis}

Multiple studies such as Menneni et al. (2008), Russo (2008), and Woody (2006) showed that CC1 and CC2 are essential parameters of W99 when calibrating the simulation model to capacity and indicated to the substantial influence of these parameters on the freeway traffic flow. Besides, Menneni et al. (2008) explain that the combined effect of $\mathrm{CC} 0, \mathrm{CC} 1$ and $\mathrm{CC} 2$ can result in multiple solutions for the desired capacity value. In this context, the current study performed an optimisation using Sensitivity Analysis (SA) which is also referred to as "what-if" or "simulation analysis". The SA is a method used for predicting the outcome of a decision given a specific range of variables; it addresses how much changes in one variable might affect the outcome. The parameters of W99 were optimised using sensitivity analysis and then these parameters are simulated in Vissim. Then, the simulation results were evaluated for travel time, the total number of vehicles in the model (which is an indication of the network throughput and capacity), queue length, queue delay, the number of stops, stop delay, the Level of Service (LOS), fuel consumption and emission. In this context, 86 simulation scenarios were defined to find a combination of parameters which provide the highest improvement in the characteristics mentioned above (i.e., a reduction in travel time, or an increase throughput). The optimisation flowchart is shown in Figure 2.

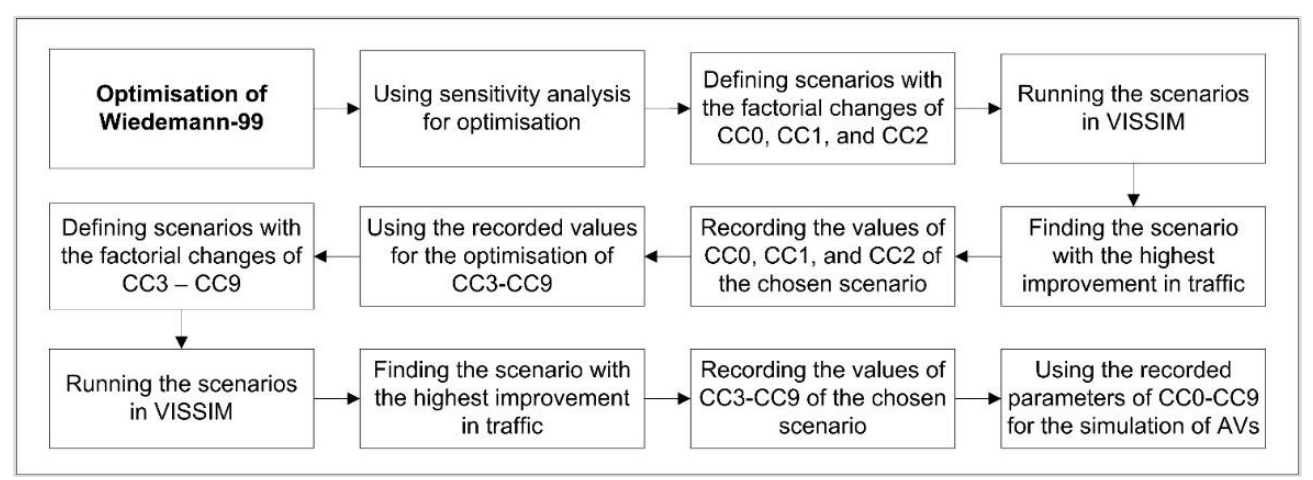

Figure 2. Optimisation flowchart

Regarding the increase or decrease of CC-parameters ${ }^{2}$, the study conducted some (trial) simulations to capture the effect of reducing CC-parameters on the simulation results. The results showed that small changes in CCparameters have negligible impacts on the simulation results. In light of this, taking account of all the possible reductions from $0-100 \%$ would have been very time-consuming and unnecessary. Hence, the study made use of three factorial percentages of $25 \%, 50 \%$ and $75 \%$ changes in the values of CC-parameters, which represent the percentages below and above them (between $0-100 \%$ ). Also, a $100 \%$ change in value was applied to some CC-parameters where it was possible, such as for CC4 (negative "following" threshold) and CC5 (positive

\footnotetext{
${ }^{1}$ CC0: Standstill Distance, CC1: Headway Time, CC2: "Following" Variation, CC3: The Threshold for Entering to "Following" Phase, CC4: Negative "Following" Threshold, CC5: Positive "Following" Threshold, CC6: Speed Dependency of Oscillation, CC7: Oscillation Acceleration, CC8: Standstill Acceleration, CC9: Acceleration at $80 \mathrm{~km} / \mathrm{h}$

${ }^{2}$ In order to avoid confusion with the parameters of Wiedemann-99, they are referred to as CC-parameters.
} 
"following" threshold). When a parameter like CC0 decreased by $25 \%$, other CC-parameters were used in the simulation without a change of value. Then, the same procedure was implemented for all the rest of the parameters one by one. In the next step, the factorial change method was used to design scenarios with the combined effect of two and three CC-parameters at a time. Note that each of the simulation scenarios was executed in Vissim and assessments were conducted on the results related to travel time, queue length, delay, and other parameters assessed in this study. After running the simulation scenarios in Vissim and analysing the results, the scenarios that provided the least travel time, fewest queues, delays and highest capacity, throughput, etc. were separated, and the related CC-parameters were selected as the optimum CC-parameters. In the next step, and after finding the optimised values of $\mathrm{CC} 0, \mathrm{CC} 1$ and $\mathrm{CC} 2$, the optimisation procedure was continued for $\mathrm{CC} 3$ to $\mathrm{CC} 9$ - one by one - while $\mathrm{CC} 0, \mathrm{CC} 1$ and $\mathrm{CC} 2$ were added to the new scenarios with their optimised values.

\subsection{Simulation}

As previously discussed in Section 3.2., In order to simulate TVs and AVs, the traffic data were analysed to find the month with the heaviest traffic (May), the month with the closest to normal traffic (September) and the month with the lightest traffic (February) of the year 2017. Then, the traffic data were reassessed to find the peak, the closest to normal, and off-peak traffic conditions within each of those three months to cover a diverse range of traffic conditions. For instance, in May, ten days with the heaviest traffic conditions were selected for the simulation of TVs. In this way, ten simulation scenarios were created where the average of those ten scenarios represent the results related to the heaviest traffic conditions within the peak month (May). Note that each simulation scenario was configured for 15 runs, and each took one hour of simulation plus an extra 10 minutes for each run to fill-up the model for the ongoing traffic of the motorway. Therefore, the results represent an average of 150 hours of simulation for peak traffic conditions within May. Then, the same procedure was adopted for the simulation of TVs for the normal and off-peak traffic conditions within the same evaluation month (May). Likewise, the simulation was performed for traffic conditions in September and February. Such a framework of simulation represents reliable results for the simulation of all traffic conditions. In addition, the final values of the simulations in this step were subsequently compared with the results from the simulations of AVs. Such a simulation procedure resulted in 90 scenarios with 1,350 hours of simulation; then, the same simulation framework was adopted for AVs. Figure 3 illustrates the overall workflow of the simulation modelling of TVs and AVs. Figure 4 also shows the breakdown of the simulaion model in this regard.

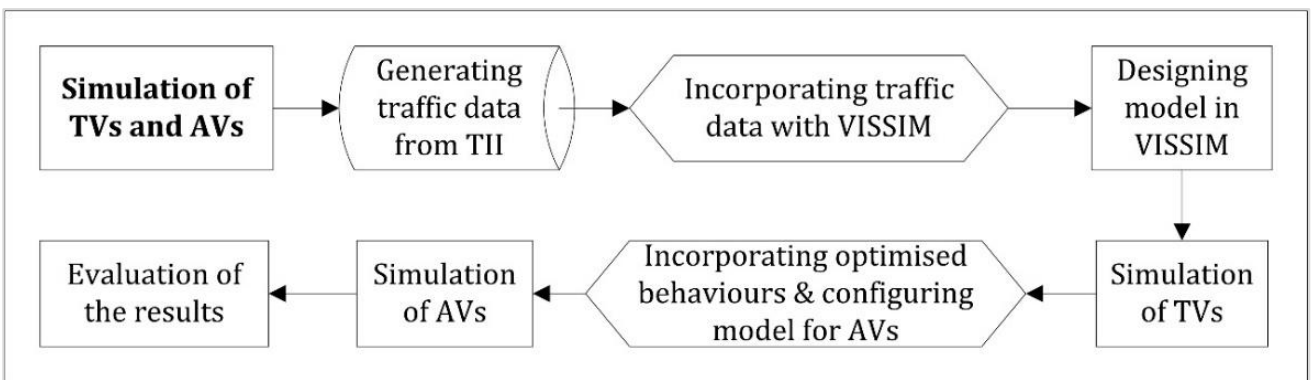

Figure 3. The overall workflow for the simulation of TVs and AVs 


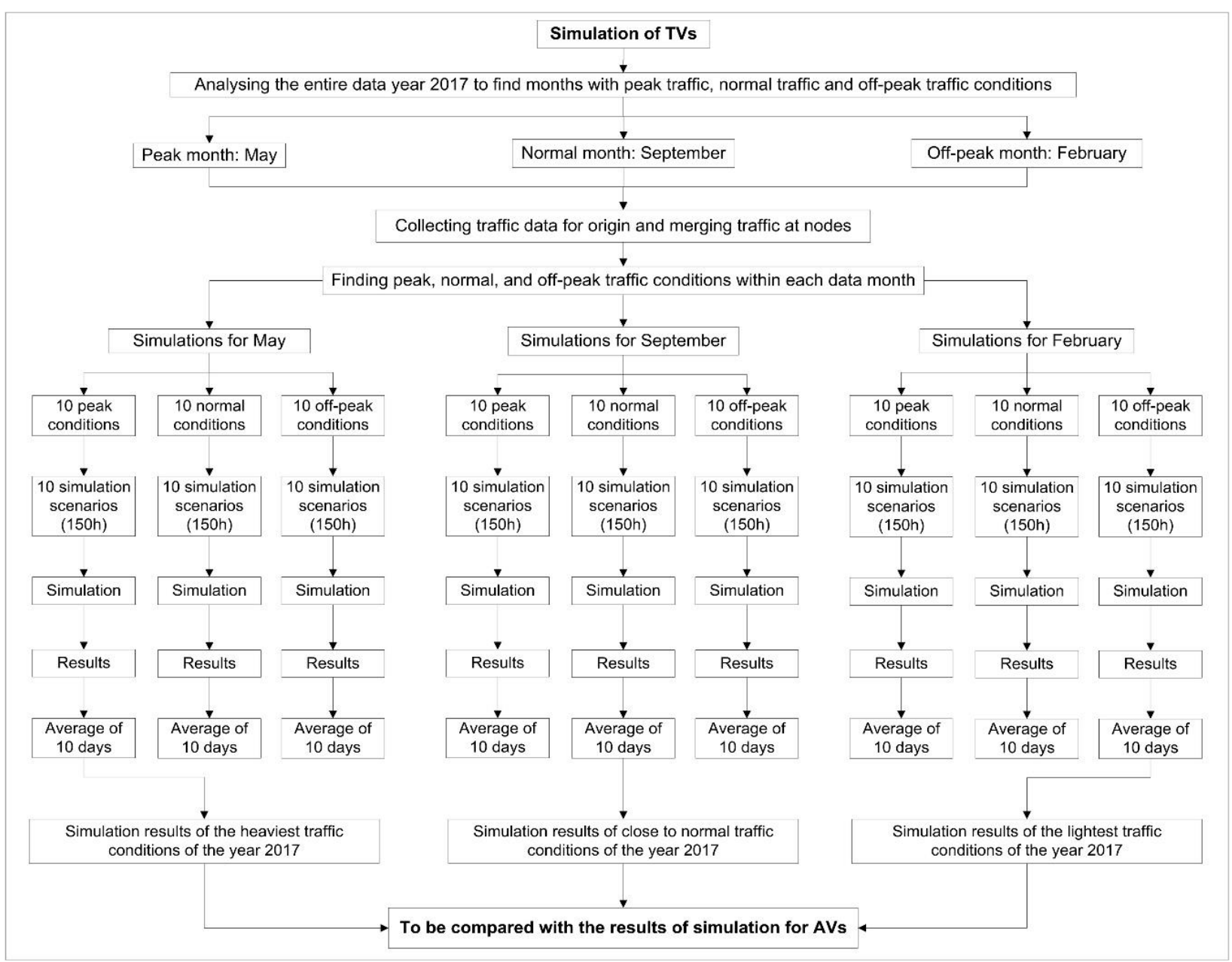

Figure 4. Breakdown of the simulation procedure for TVs

In the next step, in order to simulate the transition period for adopting AVs and the shared traffic with TVs, 11 scenarios were defined for simulation. For this, the network was designed to operate with TVs in scenario one. Then, AVs were incremented by $10 \%$ at each scenario, until they occupied the entire network in Scenario 11. The results of this evaluation offer an understanding of the quality of traffic flow with different proportions of TVs and AVs. Figure 5 illustrates the steps taken for the simulation of a transition period. Also, Table 6 represents the sharing percentage of the TVs and AVs at each scenario.

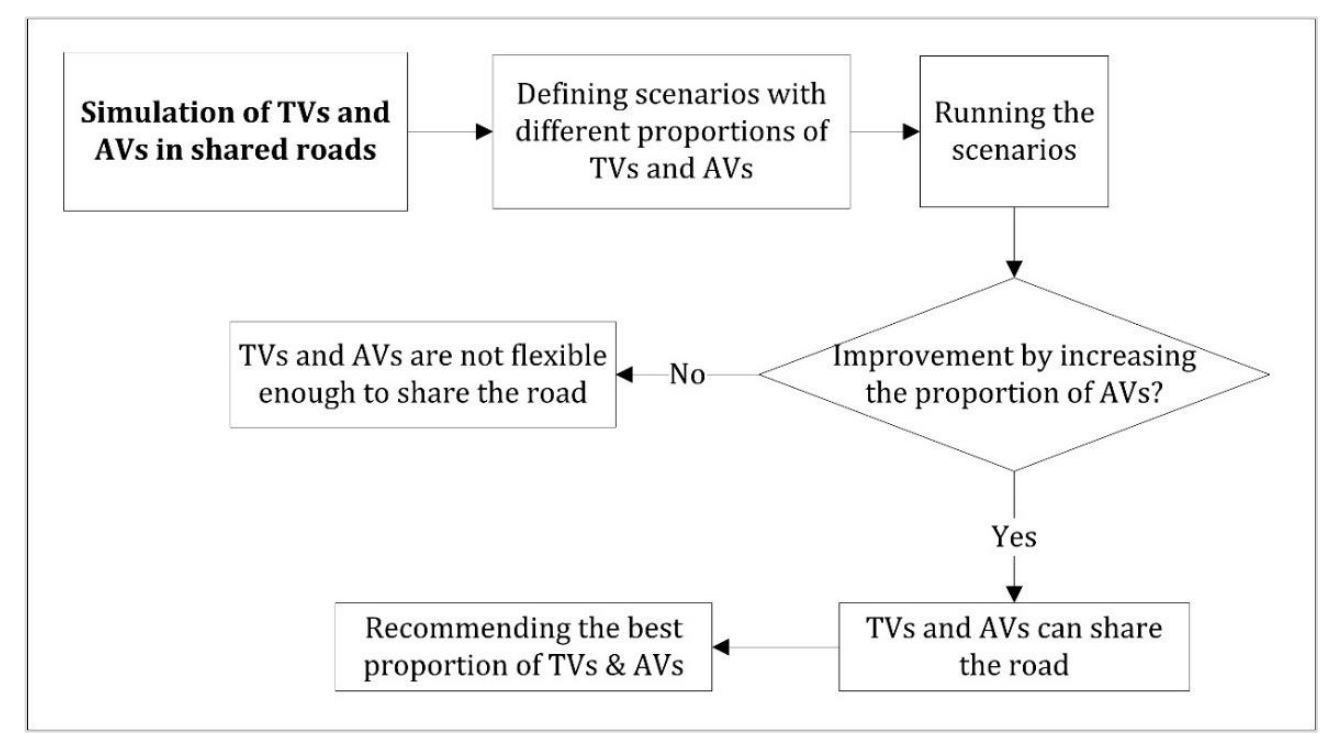

Figure 5. Simulation of the shared traffic 
Table 6. Scenarios for the simulation of TVs and AVs in shared road

\begin{tabular}{lcccccccccccc}
\hline Scenario & & $\mathbf{1}$ & $\mathbf{2}$ & $\mathbf{3}$ & $\mathbf{4}$ & $\mathbf{5}$ & $\mathbf{6}$ & $\mathbf{7}$ & $\mathbf{8}$ & $\mathbf{9}$ & $\mathbf{1 0}$ & $\mathbf{1 1}$ \\
\hline $\begin{array}{l}\text { Proportions of TVs and AVs in } \\
\text { percent }\end{array}$ & TVs & 100 & 90 & 80 & 70 & 60 & 50 & 40 & 30 & 20 & 10 & 0 \\
\cline { 2 - 10 } & AVs & 0 & 10 & 20 & 30 & 40 & 50 & 60 & 70 & 80 & 90 & 100 \\
\hline
\end{tabular}

434

435

436

437

438

439

440

441

442

443

444

445

446

447

448

449

450

451

452

453

454

Furthermore, in order to validate the simulation of this study, an assessment was conducted with the driving behaviours optimised by PTV for AVs. PTV (2018) defined three sets of driving behaviours for AVs; AV-AllKnowing, AV-Normal, and AV-Cautious, which are demonstrated later in the simulation of shared traffic in Table 12). The All-Knowing mode of driving behaviours represents AVs in the minimal distances from each other, smaller thresholds, and higher acceleration and deceleration, whereas AV-Cautious represents an opposite mode of driving behaviours. Also, AV-Normal represents a standard mode of driving behaviours where all parameters have an average value in their range. The driving behaviours suggested by PTV were used for the simulation of AVs in the normal traffic conditions of September. Then, the results were compared to those of this study. Such an evaluation shows the extent to which the optimised parameters of the current study are in line with the tuned parameters recommended by PTV.

Regarding the number of simulation runs, Byrne (2013) recommends 7 runs to achieve 0.05 confidence interval, and 0.05 coefficient of variation, and a $99 \%$ confidence level. However, Byrne (2013) indicates that more number of runs might be required when more variables are associated with the simulation model. Therefore, a higher number of simulation run was adopted in this study to achieve a meaningful prediction of the impact of AVs in multiple characteristics (travel time, fuel consumption, and others). In this regard, 10 number of runs was defined for the optimisation process, and 15 runs for the simulation of TVs and AVs under various traffic conditions. Table 7 represents the structure of the simulation procedures in this study along with the number of scenarios, and simulation time in Vissim.

Table 7. Structure of the simulation procedures

\begin{tabular}{|c|c|c|c|c|c|c|}
\hline \multirow{2}{*}{$\begin{array}{l}\text { Purpose of } \\
\text { simulation }\end{array}$} & \multirow[t]{2}{*}{ Description } & \multirow[t]{2}{*}{ \# Scenarios } & \multirow{2}{*}{$\begin{array}{c}\text { \# Runs in } \\
\text { each } \\
\text { scenario }\end{array}$} & \multicolumn{3}{|c|}{ Simulation time $(h)$} \\
\hline & & & & $\begin{array}{l}\text { Recorded for } \\
\text { assessments }\end{array}$ & Warm-up & Total \\
\hline \multirow{2}{*}{$\begin{array}{l}\text { Simulation for } \\
\text { optimisation }\end{array}$} & $\mathrm{CC} 0, \mathrm{CC} 1$, and $\mathrm{CC} 2$ & 63 & 10 & 630 & 105 & \multirow[t]{2}{*}{1,003} \\
\hline & $\mathrm{CC} 3$ to $\mathrm{CC} 9$ & 23 & 10 & 230 & 38 & \\
\hline \multirow{6}{*}{$\begin{array}{l}\text { Simulation of } \\
\text { TVs and AVs }\end{array}$} & TVs in peak traffic (May) & 30 & 15 & 450 & 75 & \multirow[t]{6}{*}{3,150} \\
\hline & AVs in peak traffic (May) & 30 & 15 & 450 & 75 & \\
\hline & TVs in normal traffic (Sep) & 30 & 15 & 450 & 75 & \\
\hline & AVs in normal traffic (Sep) & 30 & 15 & 450 & 75 & \\
\hline & TVs in off-peak (Feb) & 30 & 15 & 450 & 75 & \\
\hline & AVs in off-peak traffic (Feb) & 30 & 15 & 450 & 75 & \\
\hline \multirow{3}{*}{$\begin{array}{l}\text { Simulation of } \\
\text { shared road of } \\
\text { TVs with AVs }\end{array}$} & Peak traffic (May) & 11 & 15 & 165 & 27 & \multirow[t]{3}{*}{576} \\
\hline & Normal traffic (Sep) & 11 & 15 & 165 & 27 & \\
\hline & Off-peak traffic (Feb) & 11 & 15 & 165 & 27 & \\
\hline \multirow[t]{4}{*}{$\begin{array}{l}\text { Simulation with } \\
\text { PTV values }\end{array}$} & $\begin{array}{l}\text { AVs with All-knowing driving } \\
\text { behaviours }\end{array}$ & 10 & 15 & 150 & 25 & \multirow[t]{4}{*}{717} \\
\hline & $\begin{array}{l}\text { AVs with Normal driving } \\
\text { behaviours }\end{array}$ & 10 & 15 & 150 & 25 & \\
\hline & $\begin{array}{l}\text { AVs with cautious driving } \\
\text { behaviours }\end{array}$ & 10 & 15 & 150 & 25 & \\
\hline & $\begin{array}{l}\text { Mixed traffic of PTV-AVs with } \\
\text { TVs }\end{array}$ & 11 & 15 & 165 & 27 & \\
\hline Total & & 340 & 215 & 4,670 & 776 & 5,446 \\
\hline
\end{tabular}

\subsection{Reliability and Validity}

In this study, the simulation scenarios are tested over various simulation runs to make sure the results are internally consistent; then, the average values of the simulation runs are used as the overall results of the simulation scenario. In this regard, a constancy test named Cronbach's Alpha $(\alpha)$ is adopted to evaluate the consistency of the (initial) simulation runs. Cronbach's Alpha is a very well-known reliability test for evaluating the internal consistency of a statistical model (Heale and Twycross, 2015; Tavakol and Dennik, 2011). Once the model was tested for consistency, then it was adopted for simulations. Equation 1 shows the mathematical function of Cronbach's $\alpha$ retrieved from the study conducted by Tavakol and Dennick (2011): 
where

$$
\alpha=\frac{N * \bar{C}}{\bar{V}+(N-1) * \bar{C}}
$$

$N=$ the number of items

$\bar{C}=$ average covariance between item pairs

$\bar{V}=$ average variance

According to Siswaningsih et al. (2017), a Cronbach's $\alpha$ value of above 0.7 represents an acceptable reliability of the model results, where $\alpha$ values of above 0.8 and 0.9 are considered a good and very good reliability, respectively. In this study, the reliability assessments of Cronbach's $\alpha$ is conducted using SPSS. For this purpose, the results of the various simulation runs for each characteristic evaluated in the simulation (travel time, LOS, and others) are analysed for consistency. Additionally, the simulation results of the same traffic condition under various times of the year are compared to ensure the model results are reliable for other times of the year. For this, the simulation results of the AVs are compared for the peak traffic conditions of May, September, and February. The assessment criteria for this reliability is the Coefficient of Variance (CV), which represents the dispersion of a probability distribution, and it is the ratio of the standard deviation to mean of the data set (Zaiontz, 2019). A CV value of below 10\% would represent a good consistency, whereas below $5 \%$ is regarded as excellent consistency (Zhichu, 1989).

Regarding the validity of the simulation result; a very common method to evaluate the validity of a simulation result would be GEH statistics method to compare modelled results with observed data collected from a survey which is also called 'external validation'. However, as previously discussed in this paper, the limitations regarding the data collection in this study led to some assumptions in the model design. Also, the model of this study is a conceptual model of the M50. Furthermore, there is no experience of the official application of AVs in highway transport (other than small trials to date), so there is no observed data for them regarding their impact on travel time, queue length, and many other evaluated parameters of this study. As a result, external validation of the simulation results with empirical results was not possible in this study. However, the comparison of results from the simulation of the AVs of this study and those of PTV shows validation of the optimisation and simulation of this study.

\section{Results}

\subsection{Reliability test results}

The Chronbakh's Alpha test was conducted on the simulation results of a random traffic condition (on $4^{\text {th }}$ of May 2017). Results of the evaluation (shown in Table 8), demonstrates that nine out eleven evaluated parameters of the simulation model represented good (and very good) reliability according to Siswaningsih et al. (2017) and Taber (2018). Also, two parameters, the number of vehicles from origin to destination, and stop delay represented acceptable consistency for TVs according to the studies mentioned above. In general, the simulation model of this study represented an overall $\alpha$ value of 0.848 , which is a good reliability. Therefore, the simulation model showed to be reliable to represent consistent results.

Table 8. Reliability Assessment of the simulation model in the test condition (May, 4th)

\begin{tabular}{|c|c|c|c|c|}
\hline \multirow{2}{*}{ Evaluated parameter } & \multicolumn{3}{|c|}{ 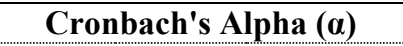 } & \multirow{2}{*}{ Reliability } \\
\hline & TVs & AVs & Average & \\
\hline Travel time & 0.913 & 0.906 & 0.910 & Very good \\
\hline Number of vehicles (origin-destination) & 0.456 & 0.851 & 0.654 & Acceptable \\
\hline Number of vehicles (total) & 0.839 & 0.986 & 0.913 & Very good \\
\hline Queue delay & 0.867 & 0.889 & 0.878 & Good \\
\hline Queue length & 0.834 & 0.883 & 0.859 & Good \\
\hline Vehicle delay & 0.855 & 0.887 & 0.871 & Good \\
\hline Stop delay & 0.773 & 0.719 & 0.746 & Acceptable \\
\hline Number of stops & 0.779 & 0.886 & 0.833 & Good \\
\hline $\mathrm{CO}$ emission & 0.825 & 0.924 & 0.875 & Good \\
\hline Fuel consumption & 0.825 & 0.924 & 0.875 & Good \\
\hline LOS & 0.929 & 0.912 & 0.921 & Very good \\
\hline Average reliability & 0.809 & 0.888 & 0.848 & Good \\
\hline
\end{tabular}




\subsection{Optimisation results}

The basis of assessing any improvement in the optimisation results was a comparison of the results of optimisation scenarios with the results of the simulation of TVs. Therefore, the results related to scenario TVs were considered as the reference category for assessing the improvement of the optimisation scenarios. In this context, the result of each 63 optimisation scenarios were compared to those of TVs, which is shown in Figure 6. In overall, scenarios 59 - with an overall improvement of $55.6 \%$ compared with the simulation result of TVs - presented the greatest improvement of all 63 scenarios adopted for optimisation. Therefore, the CCparameters related to scenario 59 were used as the optimised CC-parameters of this study and were applied to the optimisation of $\mathrm{CC} 3-\mathrm{CC} 9$. The related values of $\mathrm{CC} 0, \mathrm{CC} 1$, and $\mathrm{CC} 2$ for scenario 59 are $0.38,0.45$, and 2 , respectively. After finding the optimised values of $\mathrm{CC} 0, \mathrm{CC} 1$ and $\mathrm{CC} 2$, the optimisation procedure was continued for $\mathrm{CC} 3$ to $\mathrm{CC} 9$ - one by one - while $\mathrm{CC} 0, \mathrm{CC} 1$ and $\mathrm{CC} 2$ were added to the new scenarios with their optimised values. In order to assess any further development in the model with the optimisation of CC3CC9, the simulation results of the optimisation scenarios were compared with the results from scenario 59. In this regard, any improvement in the results of scenario 59 was considered an enhancement to the optimisation process. Otherwise, the new optimisation scenarios (for CC3-CC9) were being rejected if they deteriorated the results of scenario 59. In this regard, the simulation results related to the optimisation of CC3-CC9 revealed that none of the optimisation scenarios related to CC3-CC9 could improve the results of scenario 59; most deteriorated them. Therefore, the results indicated that, except for $\mathrm{CC} 0, \mathrm{CC} 1, \mathrm{CC} 2$, the rest of the Wiedemann parameters evaluated in this study should not be changed. Such a result had also been indicated in a report by Wisconsin DOT (2018).

526

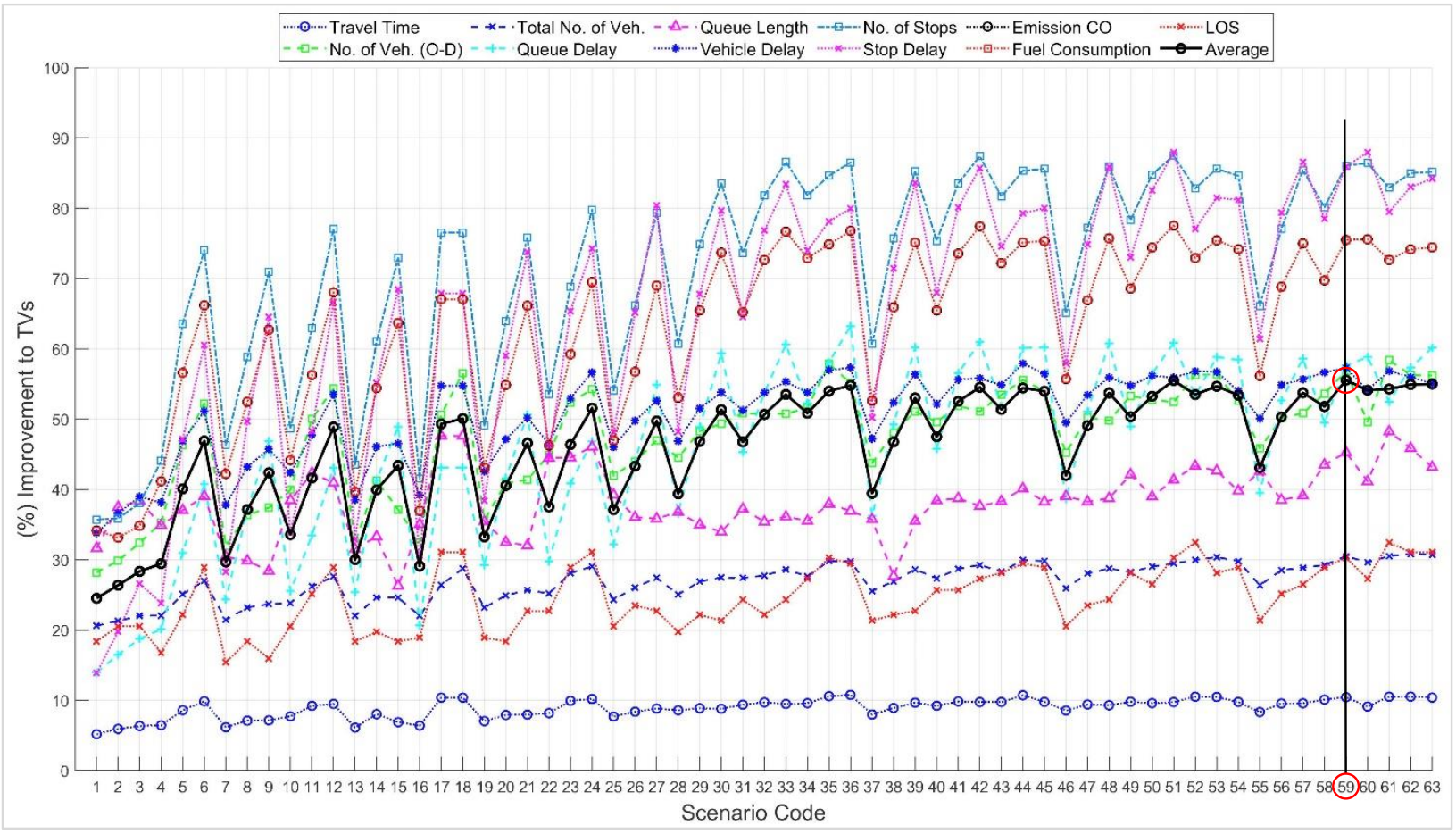

Figure 6. Improvement percentage of the optimisation scenarios related to $\mathrm{CC} 0, \mathrm{CC} 1$, and $\mathrm{CC} 2$ compared to the base scenarios (traditional road traffic)

One may claim that AVs would have different behaviours than human and W99 was defined for human driving behaviour. In light of this, some of the CC-parameters like CC6 (Speed Dependency of Oscillation) should be reduced to 0 or they should be changed; which is a valid concern. However, since autonomous vehicles are not yet officially operating on the streets, there is not a solid reference regarding their exact driving behaviours. Therefore, the current study did not make such amendments in the values of CC3-CC9. Table 9 represents the optimised values for AV driving behaviours recommended by this study. Calvert et al (2020) also adopted a 
Table 9. Recommended values for the driving behaviours of AVs

\begin{tabular}{clccc}
\hline $\begin{array}{c}\text { Model } \\
\text { Parameter }\end{array}$ & Definition & W99 & Status & Recommended \\
\hline CC0 & Standstill Distance & 1.50 & Changed & 0.38 \\
CC1 & Headway Time & 0.90 & Changed & 0.45 \\
CC2 & "Following" Variation & 4.00 & Changed & 2.00 \\
CC3 & The Threshold for Entering to "Following" Phase & -8.00 & Not changed & -8.00 \\
CC4 & Negative "Following" Threshold & -0.35 & Not changed & -0.35 \\
CC5 & Positive "Following" Threshold & 0.35 & Not changed & 0.35 \\
CC6 & Speed Dependency of Oscillation & 11.44 & Not changed & 11.44 \\
CC7 & Oscillation Acceleration & 0.25 & Not changed & 0.25 \\
CC8 & Standstill Acceleration & 3.50 & Not changed & 3.50 \\
CC9 & Acceleration at 80 km/h & 1.50 & Not changed & 1.50 \\
\hline
\end{tabular}

543

544

545

546

547

548

549

550

551

552

553

554

555

556

557

558

559

560

561

562

563

564

565

566

567

The study also estimated how the characteristics in Table 8 are affected by driving behaviour changes. The results from this evaluation provide a useful guideline on the extent to which driving behaviour must change to attain the desired improvements in travel time, queues, and all the other assessed characteristics. In this regard, the results of all 63 optimisation scenarios were sorted for each characteristic in Table 8. Then, scenarios with the greatest improvement in each characteristic (i.e., the lowest value of travel time) were selected for further assessments. The trial evaluation showed that 20 scenarios would provide a sufficient range of results for addressing the impact of $\mathrm{CC} 0, \mathrm{CC} 1$, and $\mathrm{CC} 2$ on each characteristic. The idea was to find which factorial changes of $\mathrm{CC}, \mathrm{CC} 1$, and $\mathrm{CC} 2$ have had the highest frequency (i.e., the highest impact) in those top 20 scenarios sorted for each characteristic. These assessments represent the importance of each of the factorial changes. The assessment of the frequency of the factorial changes defined for $\mathrm{CC} 0, \mathrm{CC} 1$, and $\mathrm{CC} 2$ (shown in Table 10) revealed that $\mathrm{CC} 1$ with $75 \%$ reduction $(0.23)$ from its initial value $(0.9)$ had the highest impact (of all factorial changes) on the quality of traffic flow. In total, CC1 (0.23) was used 93 times in 180 evaluated scenarios ( 20 scenarios for a total of 9 factorial changes) with the greatest improvements in the characteristics of traffic in this study. Such a result implies that $\mathrm{CC} 1$ when it is considered 0.23 , plays an essential role in simulations related to the improvement in the quality of traffic. Overall, $\mathrm{CC} 1(0.23)$ had the highest impact on the reduction of travel time, queue length, LOS, and increasing the number of vehicles. Moreover, results showed that $\mathrm{CC} 2$ had the second-highest impact on the quality of traffic (after $\mathrm{CC} 1$ ) when $\mathrm{CC} 2$ was decreased by $75 \%$ (1) from its initial value (4). In total, CC2 with the value of 1 was used 85 times in 180 scenarios with the most considerable improvements in the characteristics of traffic in this study. $\mathrm{CC} 2$, when it was considered 1 , had the highest impact on the reduction of queue delay, the number of stops, stop delay, fuel consumption and $\mathrm{CO}$ emissions.

Table 10. Frequency of the reduced values of $\mathrm{CC} 0, \mathrm{CC} 1$, and $\mathrm{CC} 2$ in the top 20 optimisation scenarios

\begin{tabular}{|c|c|c|c|c|c|c|c|c|c|}
\hline CC-parameter & & CCO & & & CC1 & & & $\mathrm{CC2}$ & \\
\hline Reduced value & 1.13 & 0.75 & 0.38 & 0.68 & 0.45 & 0.23 & 3 & 2 & 1 \\
\hline Travel time & 5 & 5 & 7 & 0 & 6 & 14 & 5 & 6 & 5 \\
\hline Number of Vehicles & 3 & 7 & 8 & 2 & 6 & 12 & 3 & 6 & 9 \\
\hline Queue length & 3 & 8 & 9 & 1 & 8 & 11 & 4 & 5 & 4 \\
\hline Queue delay & 5 & 5 & 6 & 4 & 7 & 8 & 0 & 7 & 13 \\
\hline Number of Stops & 5 & 5 & 6 & 4 & 7 & 9 & 1 & 7 & 12 \\
\hline Stop delay & 4 & 5 & 8 & 5 & 7 & 7 & 1 & 5 & 13 \\
\hline Fuel consumption & 5 & 6 & 5 & 4 & 7 & 9 & 1 & 7 & 12 \\
\hline CO emission & 5 & 6 & 5 & 4 & 7 & 9 & 1 & 7 & 12 \\
\hline LOS & 5 & 6 & 7 & 0 & 6 & 14 & 5 & 4 & 5 \\
\hline Total & 40 & 53 & 61 & 24 & 61 & 93 & 21 & 54 & 85 \\
\hline
\end{tabular}

\subsection{Simulation results of TVs and AVs in Various Traffic Conditions}

As previously discussed in the methods of this paper, the simulation of TVs and AVs was conducted over 180 scenarios, with 3,150 hours of simulation. Table 11 and Figure 8 represent a comparison of results from the simulation of TVs and AVs under the heaviest traffic hours of the year (peak traffic in May), the normal traffic hours in the month with normal traffic (in September), and the lightest traffic hours of the year in the month with off-peak traffic. Figure 7 also illustrates a screen snip of the TVs and AVs' traffic flow on each of the traffic conditions. 
a) Peak, TVs

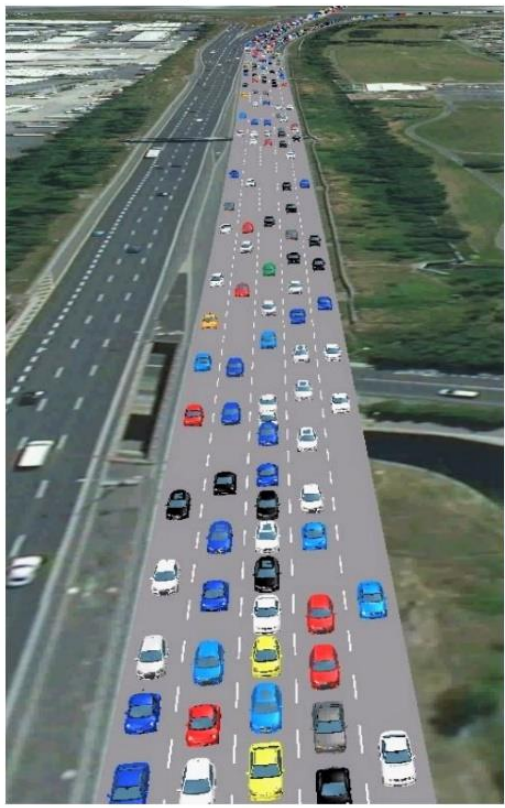

b) Peak, AVs

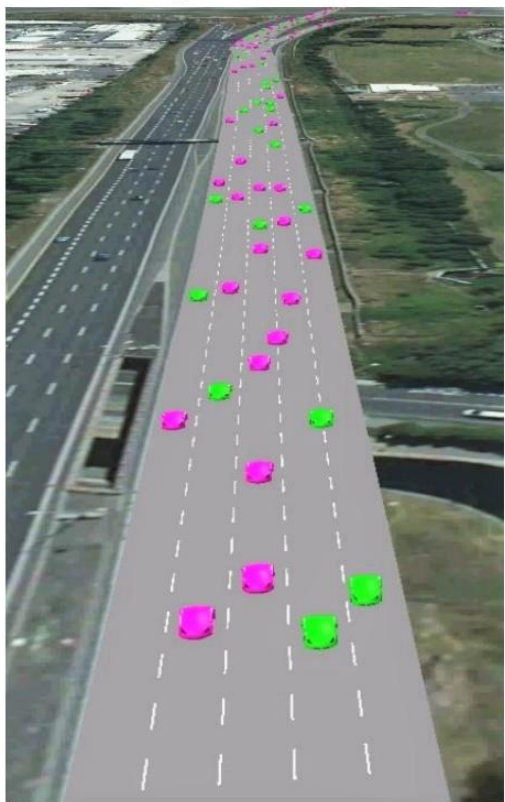

c) Normal, TVs

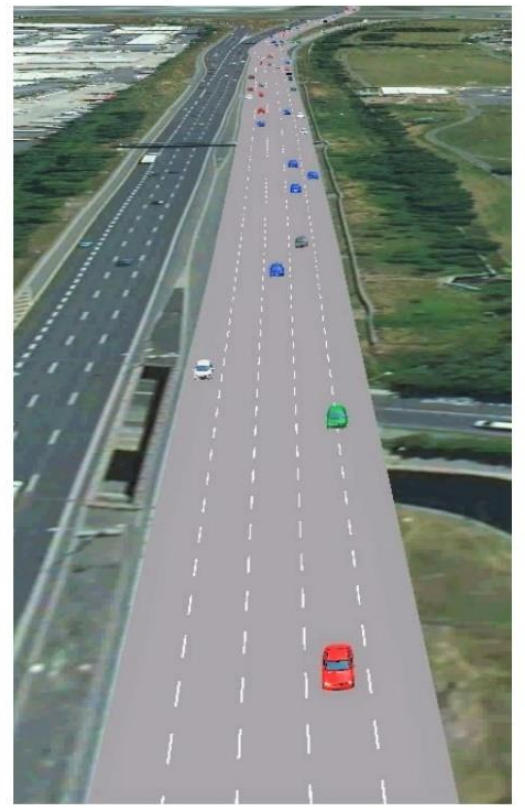

d) Normal, AVs

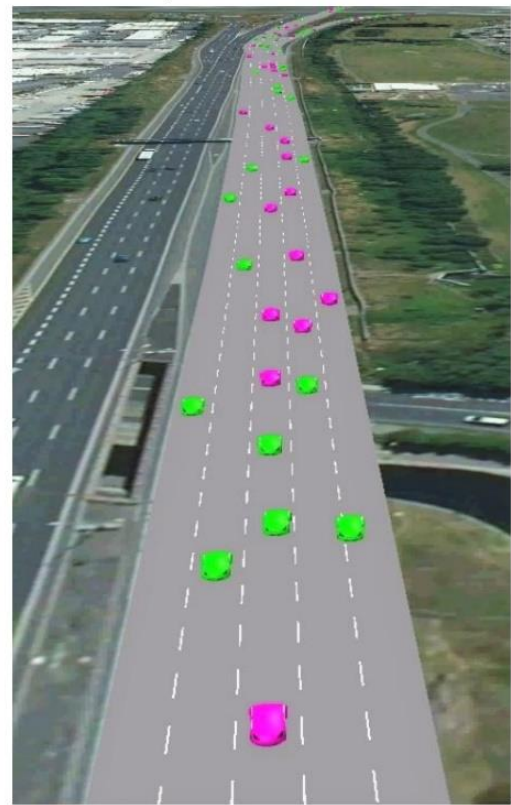

e) Off-Peak, TVs

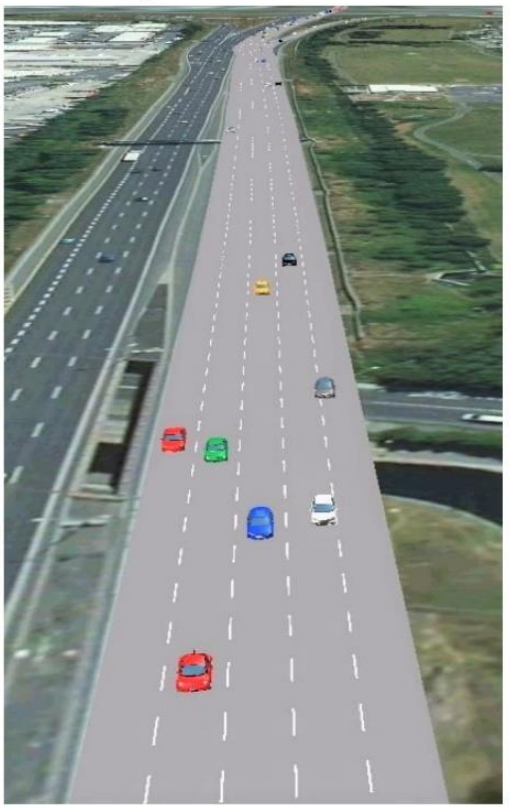

f) Off-Peak, AVs

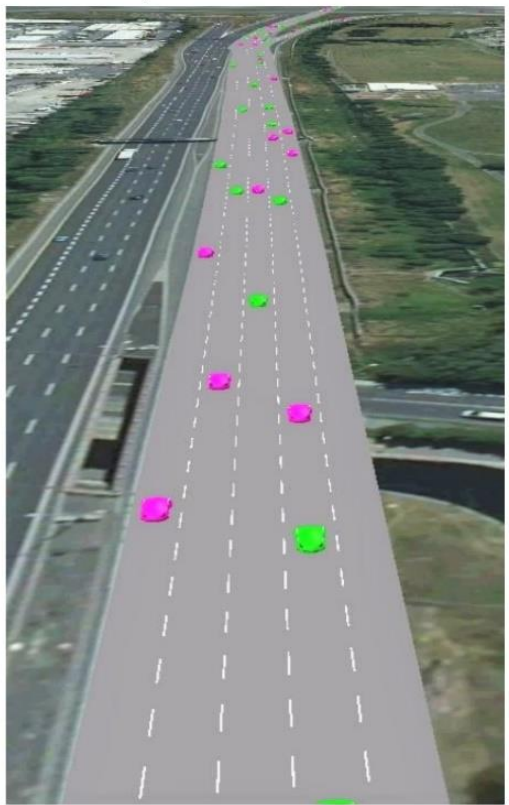

Figure 7. Simulation of TVs and AVs in the heaviest, near normal, and lightest traffic hours of the year

As demonstrated in Table 11 and Figure 8, in the first look, AVs achieved slightly higher improvements in the normal traffic hours, followed by off-peak traffic hours. However, considering that the assessment is done in percentage terms, and there is a substantial difference between the magnitude of the improvement of traffic flow in peak traffic condition, and the other two conditions. For example the magnitude of $10 \%$ improvement in the LOS during the peak traffic condition would be much higher than that of the off-peak traffic condition. Therefore, it could be stated that AVs provided much higher improvement in the quality of traffic in the peak traffic condition than the normal and off-peak traffic conditions, especially in queue length and queue delay. AVs in the off-peak traffic hours also showed smaller improvements in some parameters such as travel time and in the total number of vehicles on the road than they did during peak and normal traffic hours. One reason for the small improvements in these measures during the off-peak traffic hours could be the limitations defined for AVs such as the speed limit of $100 \mathrm{~km} / \mathrm{h}$ and the constraints related to their acceleration function, described in methods. 
Table 11. Numerical results of the simulation of TVs and AVs

\begin{tabular}{|c|c|c|c|c|c|c|}
\hline \multirow[t]{2}{*}{ Evaluated Parameter } & \multicolumn{2}{|c|}{$\begin{array}{l}\text { Average of } \mathbf{1 0} \text { peak } \\
\text { traffic hours in May (the } \\
\text { heaviest traffic conditions } \\
\text { of the year 2017) }\end{array}$} & \multicolumn{2}{|c|}{$\begin{array}{l}\text { Average of 10 normal } \\
\text { traffic } \text { hours in } \\
\text { September (normal traffic } \\
\text { conditions of the year } \\
\text { 2017) }\end{array}$} & \multicolumn{2}{|c|}{$\begin{array}{l}\text { Average of } 10 \text { off-peak } \\
\text { traffic hours in } \\
\text { February (the lightest } \\
\text { traffic conditions of the } \\
\text { year 2017) }\end{array}$} \\
\hline & TVs & AVs & TVs & AVs & TVs & AVs \\
\hline Travel Time (hh:mm:ss) & 03:09:51 & 02:45:06 & $02: 30: 35$ & 02:05:01 & $02: 02: 50$ & 01:50:09 \\
\hline Number of Vehicles (O-D) & 1,362 & 2,182 & 1,308 & 1,868 & 1,826 & 2,593 \\
\hline Number of Vehicles (Total) & 41,655 & 50,502 & 33,900 & 39,618 & 28,881 & 33,060 \\
\hline Queue Delay (hh:mm:ss) & $02: 23: 28$ & 00:52:31 & 00:54:45 & 00:04:20 & 00:11:51 & 00:00:16 \\
\hline Queue Length (km) & 4.03 & 1.97 & 0.91 & 0.02 & 0.23 & 0.00 \\
\hline Number of Stops & 1,382 & 200 & 402 & 15 & 74 & 1 \\
\hline Stop Delay (hh:mm:ss) & 00:29:44 & 00:02:03 & $00: 10: 20$ & 00:00:27 & 00:02:13 & 00:00:02 \\
\hline CO Emission (tons) & 2.53 & 0.66 & 0.94 & 0.19 & 0.29 & 0.12 \\
\hline Fuel Consumption (litres) & 137,118 & 35,832 & 51,030 & 10,169 & 15,435 & 6,440 \\
\hline LOS Value (1-6) & 4.43 & 3.09 & 3.18 & 1.61 & 1.71 & 1.03 \\
\hline
\end{tabular}

Improvement Percentage of the AVs compared to TVs

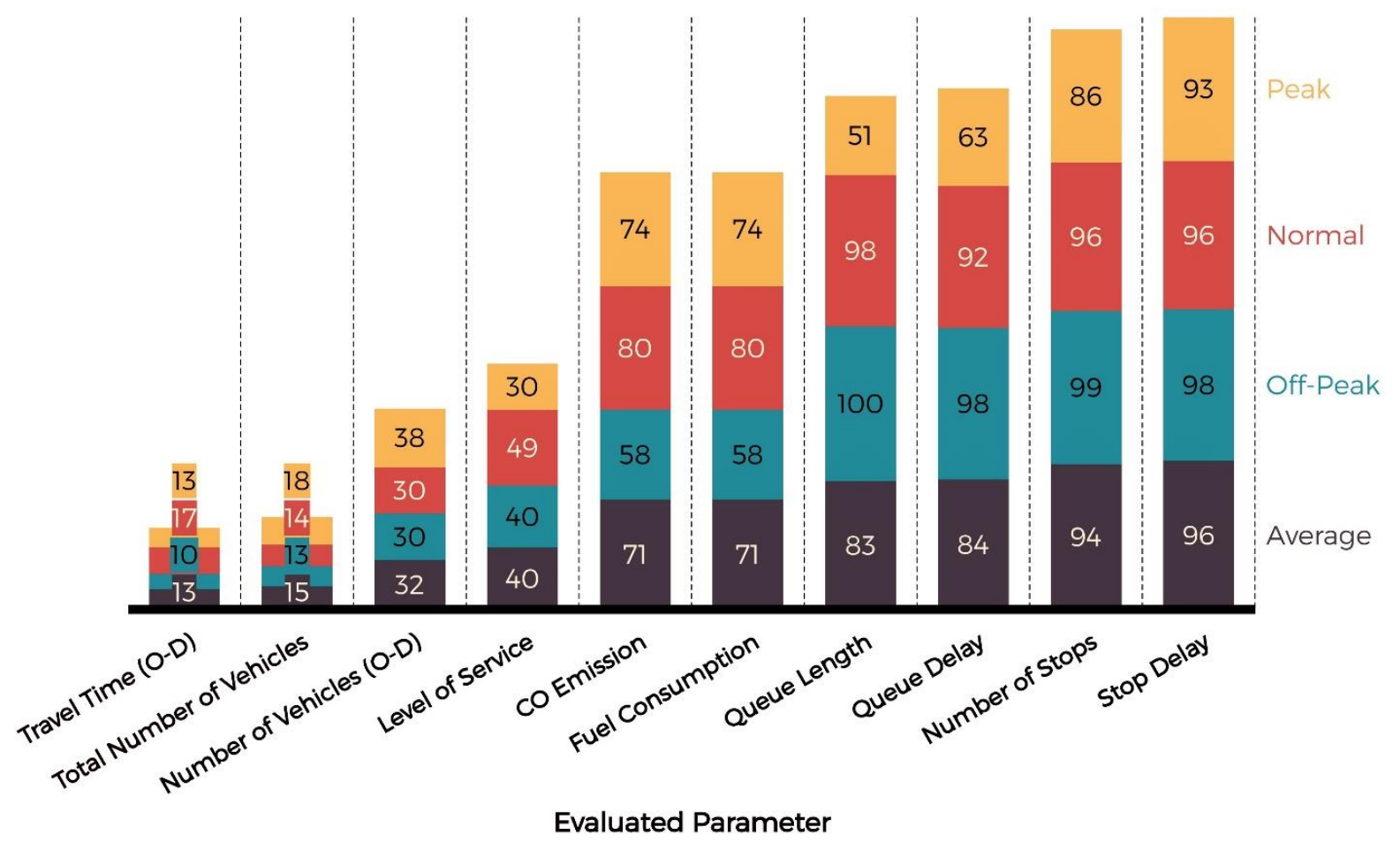

Figure 8. Comparison of TVs and AVs in the heaviest, near normal, and lightest traffic hours of the year 
It is worth noting that due to the vastness of the simulation study and the abundance of the evaluation parameters, the study could not incorporate additional models for the calculation of $\mathrm{CO}$ emissions. Hence, the study relied on the Vissim outputs in this regard. Also, the AVs of this study were assumed to be operating with combustion engines. However, the authors believe that real AVs would be full-electric or hybrid with a combustion engine. Therefore, real AVs would be expected to represent a higher reduction in fuel consumption and $\mathrm{CO}$ emissions than what the AVs of this study have demonstrated.

\subsection{Simulation results of the shared road (transition from TVs to AVs)}

Various scenarios with different proportions of TVs and AVs on the road were simulated for peak, normal, and off-peak traffic conditions of the year 2017. For this purpose, a random day from 2017 was simulated from each of the three evaluated months: May (heaviest traffic of the year), September (close to normal traffic), and February (lightest traffic). The simulation results were evaluated for the highway characteristics explained in Table 8. The improvement for each characteristic was calculated - for each of the shared scenarios - and compared with the results from the simulation of TVs, which were the reference category for the analysis. The selected day for the simulation of the TV-AV shared road in the heaviest traffic condition of the year 2017 was the $16^{\text {th }}$ of May, which was a random day that represents those days with the heaviest traffic hours of the year. The simulation results (demonstrated in Figure 9) showed that travel time, queue length, queue delay, $\mathrm{CO}$ emission, fuel consumption, and LOS were reduced with an increase in the share of AVs on the road. On the other hand, the number of vehicles from the origin to destination $(\mathrm{O}-\mathrm{D})$, and the total number of vehicles in the model were increased with an increase in the share of AVs. According to the results represented in Figure 9, when AVs comprised $100 \%$ of the network, the number of stops and length of stop delay were reduced by about $86 \%$ and $93 \%$, respectively. Such a substantial reduction in the number of stops and the length of stop delay could be an indication of the efficient interaction of AVs. After stops and stop delay time, fuel consumption and $\mathrm{CO}$ emissions were the characteristics that had the next greatest reductions. In general, a network with an equal proportion of TVs and AVs (50\%-50\%) provided $41.3 \%$ improvement in the quality of traffic, whereas a road entirely populated by AVs demonstrated a 57.6\% improvement. Tomás et al (2020) also found this result, that with lower proportions of AVs that emissions savings were less. Such an evaluation indicates how efficient a road shared by TVs and AVs can be in improving traffic quality, and how much a dedicated lane for AVs can be beneficial in this matter.

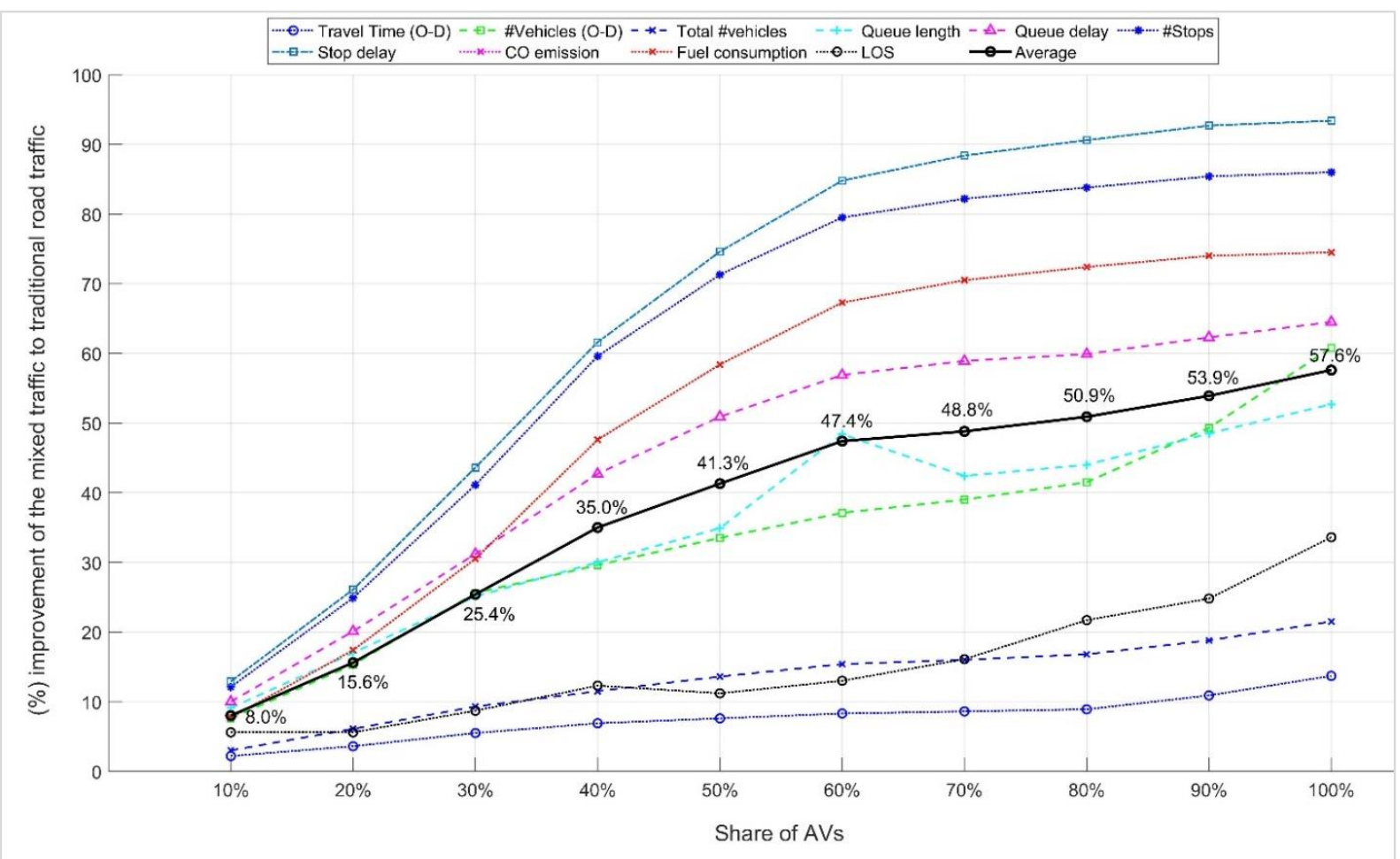

Figure 9. Improvement percentage of the shared traffic compared to traditional road traffic in May 
Also, the shared road of TVs and AVs was simulated in the near normal traffic condition. The selected day for this assessment was the $25^{\text {th }}$ of September, which represents the days with normal traffic hours. Figure 10 represents the improvement of each simulation scenario compared with the results from the simulation of TVs in this regard. According to the results in Figure 10, when AVs accounted for $100 \%$ of road traffic, the queue length and queue delay and the number of stops and stop delay decreased by more than $95 \%$. Additionally, fuel consumption and $\mathrm{CO}$ emissions were reduced by about $82 \%$ (overlapped in the Figure by similar values). In general, a network with a $50 \%$ share of AVs provided a $50.0 \%$ improvement in the quality of traffic, whereas a road network entirely populated by AVs demonstrated $69.8 \%$ improvement.

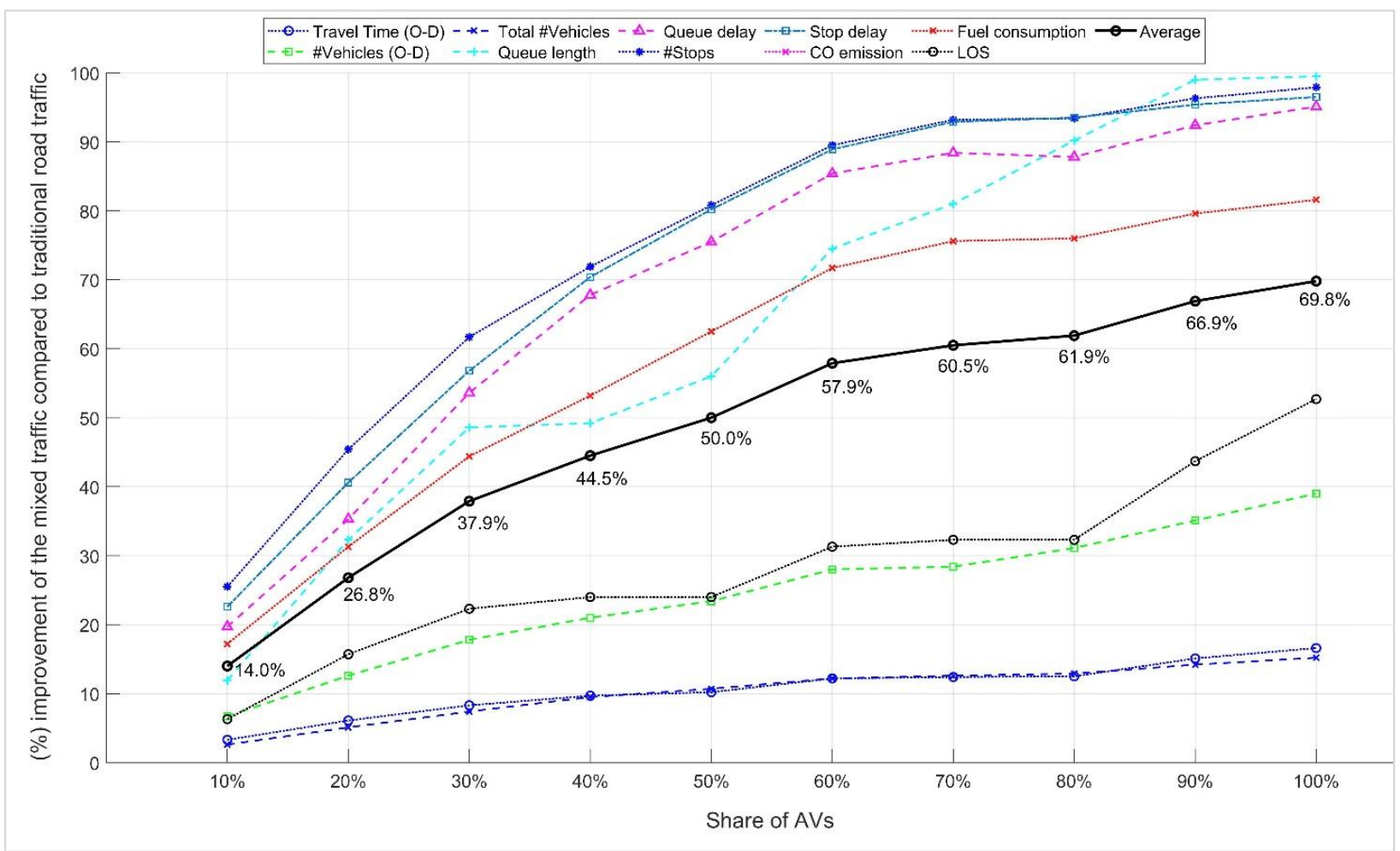

Figure 10. Improvement percentage of the shared traffic compared to traditional road traffic in September

Furthermore, the shared road of TVs and AVs was simulated in the lightest traffic condition of the year 2017. The selected day for this assessment was the 18th of February, which represents the days with the lightest traffic of the year. Figure 11 shows that when AVs represented $100 \%$ of the traffic, the number of stops, queue length, and delay were almost eliminated from the road. In general, a network with a $30 \%$ share of AVs provided a $59.9 \%$ improvement in the quality of traffic (in the lightest traffic condition), whereas a road network entirely populated by AVs demonstrated a $63.4 \%$ improvement (only $3.5 \%$ improvement). 


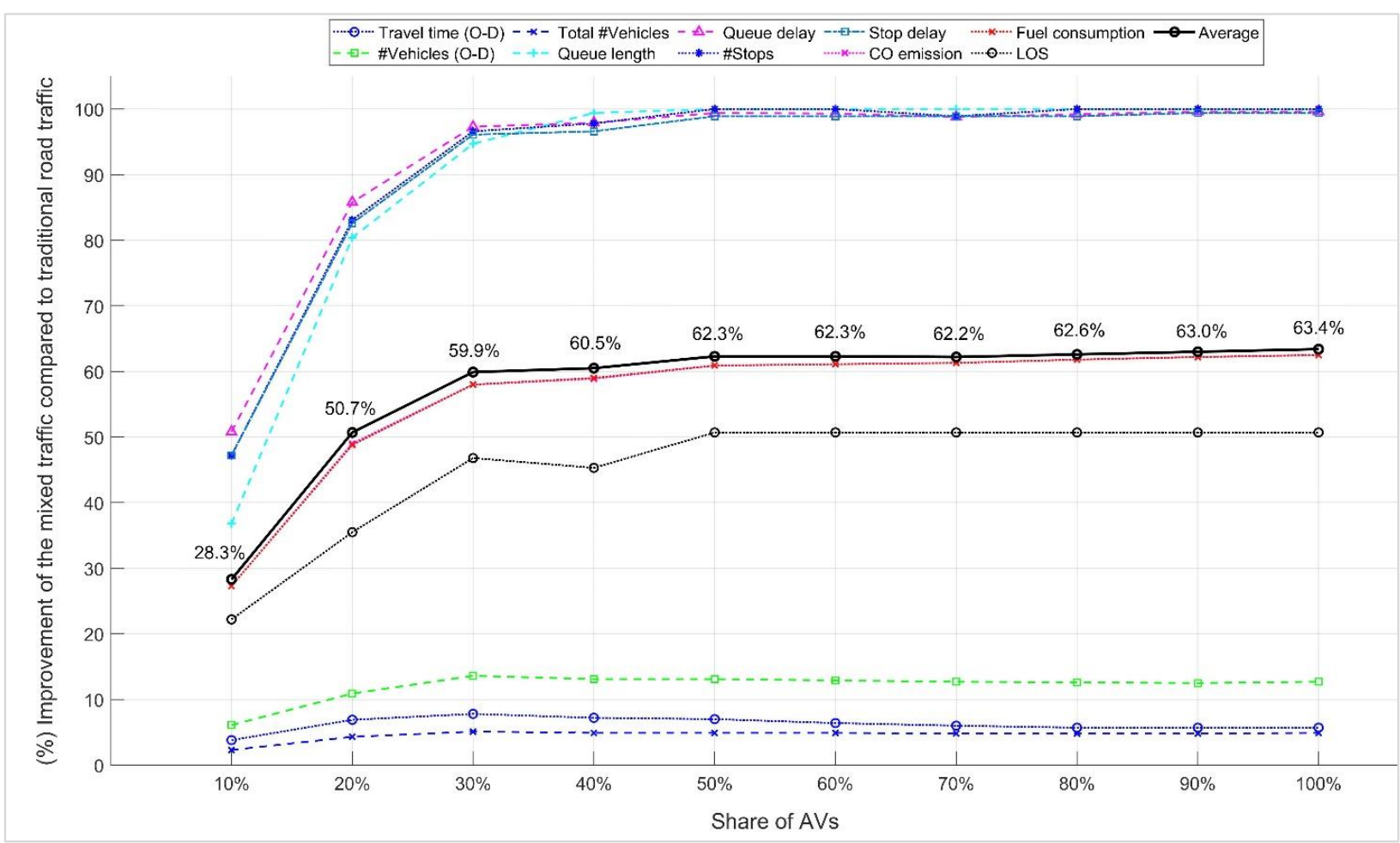

Figure 11. Improvement percentage of the shared traffic compared to traditional road traffic in February

Figure 12 also represents an overview of the simulation of the transition period. This Figure shows the average improvement of the shared scenarios for the peak, normal, and off-peak traffic conditions compared to a road entirely operated by TVs. As shown in Figure 12, dedicating 100\% of the road traffic to AVs or devoting a dedicated lane for AVs in peak and normal traffic hours might be as efficient as a shared road with $60 \% \mathrm{AVs}$. Likewise, a $30 \%$ share of the AVs in off-peak traffic conditions provides approximately the same improvement as a $100 \%$ share of them. In addition, this Figure demonstrates the average improvement of the AVs compared to TVs for all three shared traffic conditions throughout the transition period. Also, Figure 13 illustrates a screen snip of the traffic flow in different penetration of AVs during the transition period.

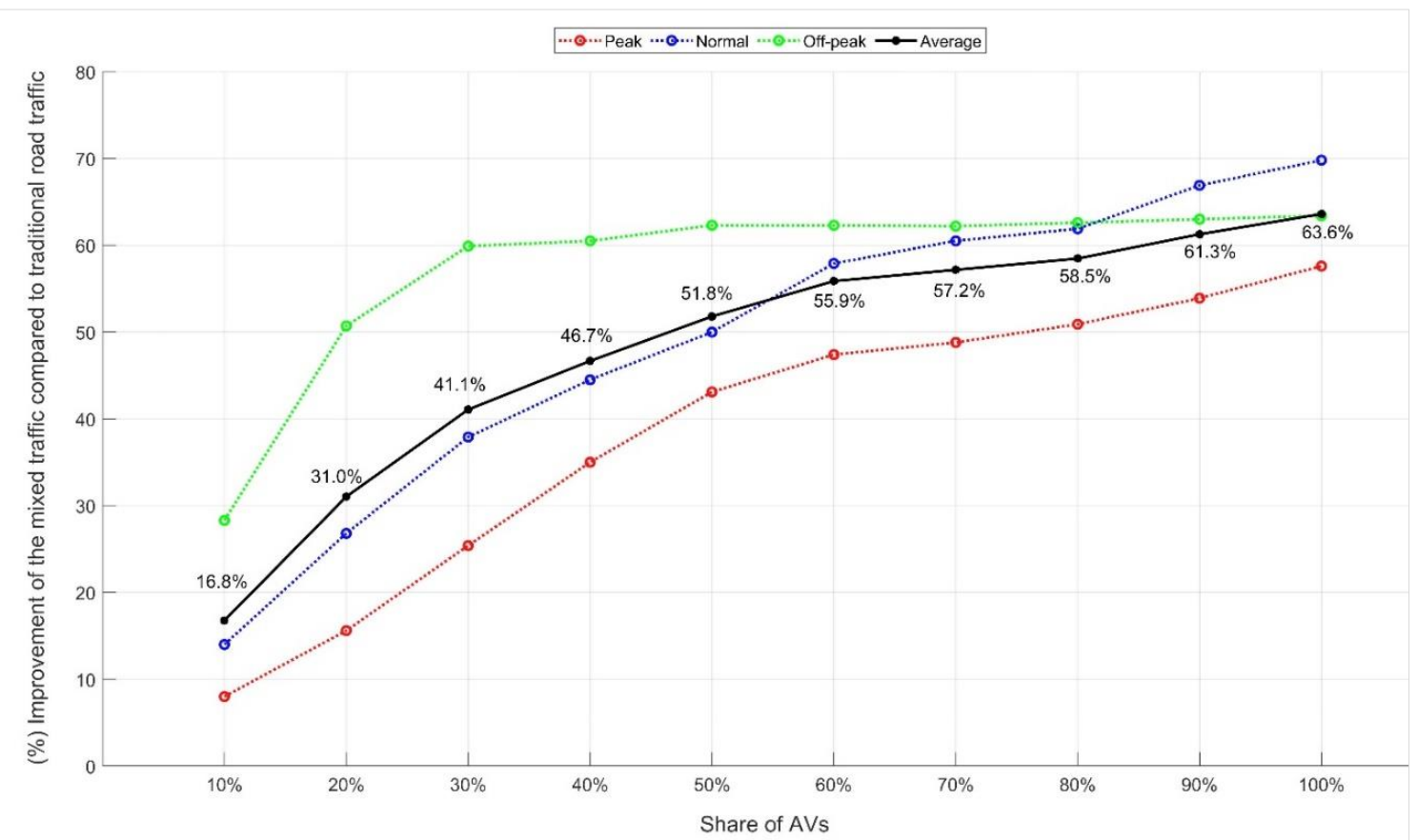

Figure 12. Transition period at a glance 


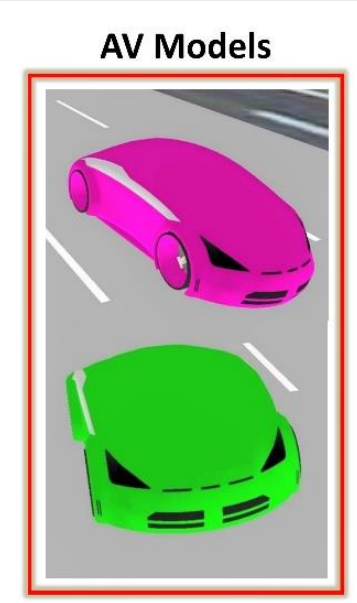

d) $30 \% \mathrm{AVs}$

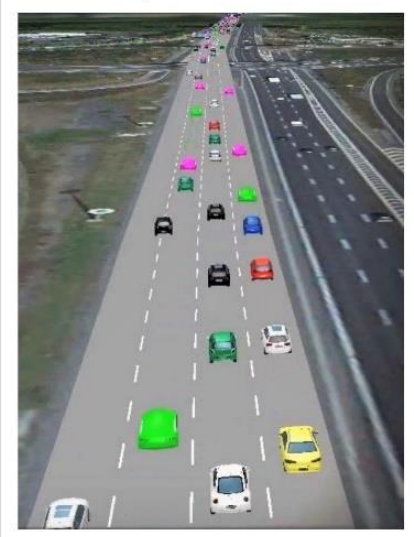

h) $70 \%$ AVs

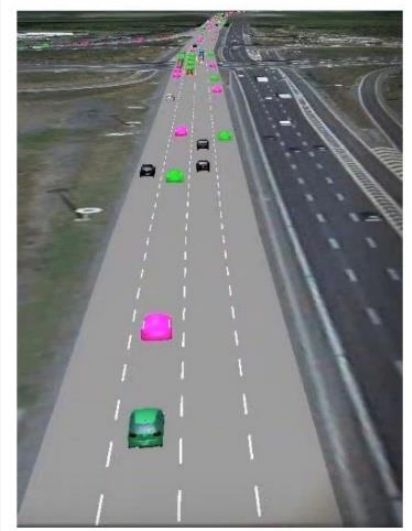

a) $0 \% \mathrm{AVs}$

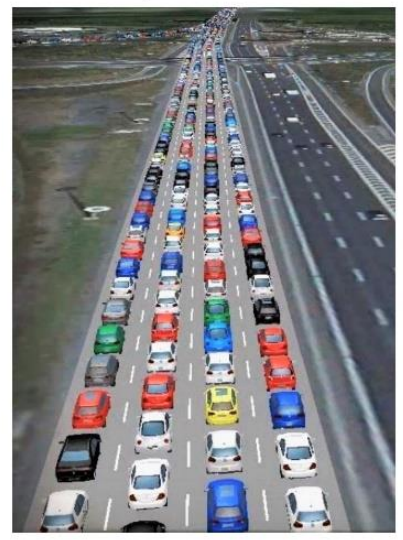

e) $40 \%$ AVs

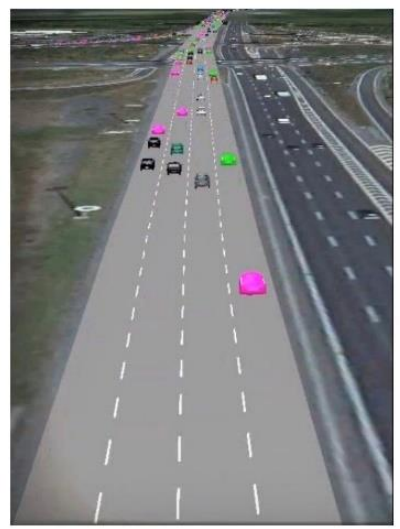

i) $80 \%$ AVs

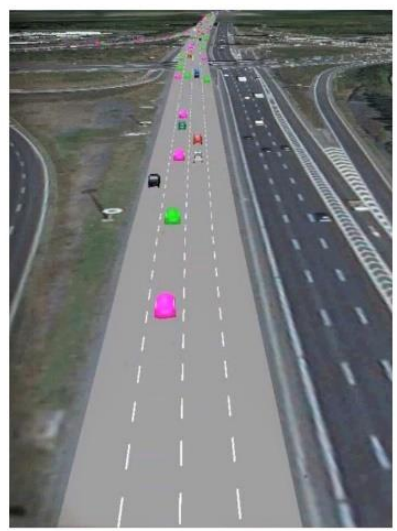

b) $10 \% \mathrm{AVs}$

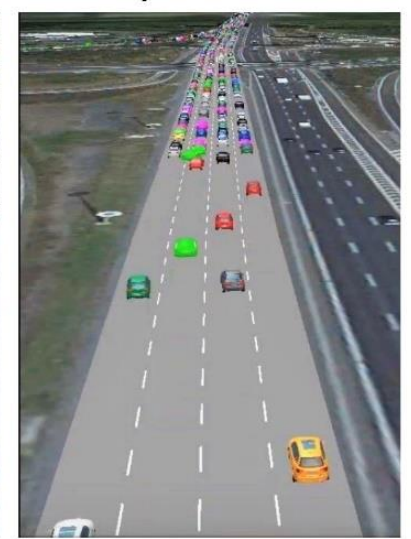

f) $50 \% \mathrm{AVs}$

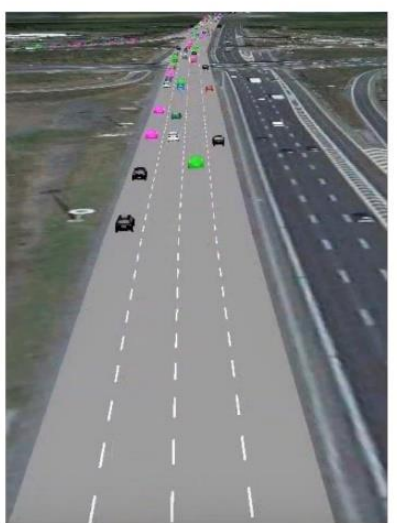

j) $90 \%$ AVs

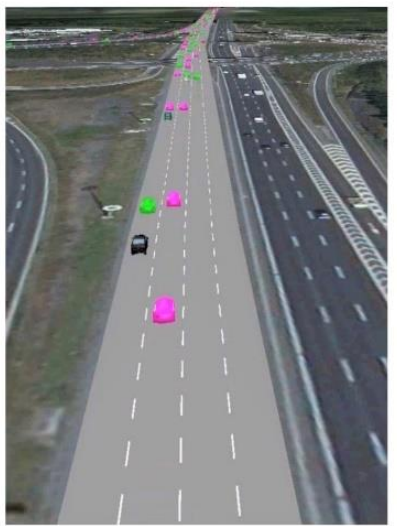

c) $20 \% \mathrm{AVs}$

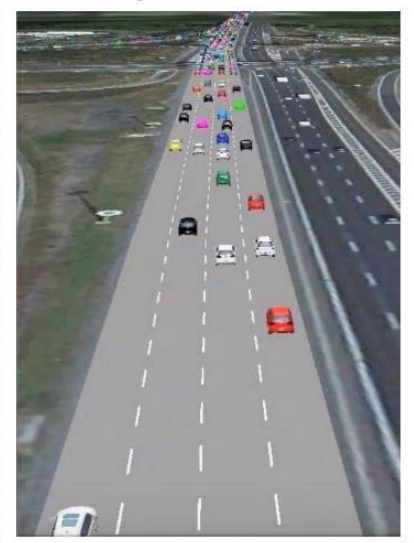

g) $60 \%$ AVs

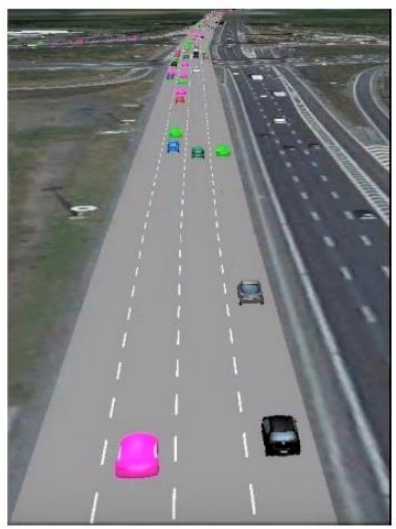

k) $100 \%$ AVs

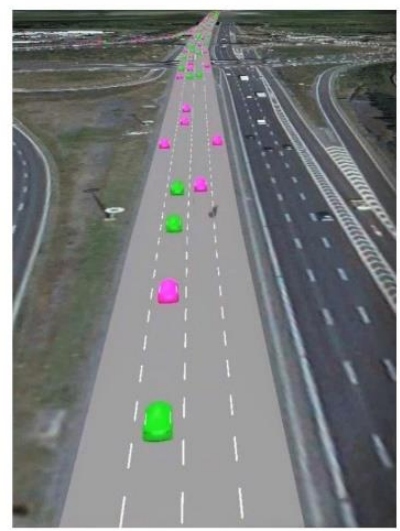

Figure 13. Simulation of the shared traffic in various penetration of AVs

\subsection{Validation by the simulation of AVs with PTV driving behaviours}

As previously argued in the methodology of this paper, PTV (2018) defined three sets of driving behaviours for AVs; AV All-Knowing, AV-Normal, and AV-Cautious, which are demonstrated in Table 12. However, to the best of the authors' knowledge, there is no previous simulation of the AVs using PTV driving behaviours in the scale of the simulation model of this study. Therefore, in this study, AVs with PTV driving behaviours are simulated under 10 normal traffic hours (in 10 days) in September to avoid any probable high or low variations of the results in the peak or off-peak traffic conditions using these driving behaviours. 
Table 12. Various autonomous driving logics defined by PTV and those of this study

\begin{tabular}{|c|c|c|c|c|c|}
\hline \multirow{2}{*}{$\begin{array}{c}\text { Model } \\
\text { parameter }\end{array}$} & \multirow{2}{*}{ W99 } & \multirow{2}{*}{ This study } & \multicolumn{3}{|c|}{ AV driving logics, defined by PTV } \\
\hline & & & All-knowing & Normal & Cautious \\
\hline $\mathrm{CCO}$ & 1.5 & 0.38 & 1 & 1.5 & 1.5 \\
\hline CC1 & 0.9 & 0.45 & 0.6 & 0.9 & 1.5 \\
\hline $\mathrm{CC2}$ & 4 & 2 & $\mathbf{0}$ & $\mathbf{0}$ & 0 \\
\hline $\mathrm{CC3}$ & -8 & -8 & -6 & -8 & -10 \\
\hline $\mathrm{CC4}$ & -0.35 & -0.35 & -0.1 & -0.1 & -0.1 \\
\hline CC5 & 0.35 & 0.35 & 0.1 & 0.1 & 0.1 \\
\hline CC6 & 11.44 & 11.44 & $\mathbf{0}$ & $\mathbf{0}$ & 0 \\
\hline CC7 & 0.25 & 0.25 & 0.1 & 0.1 & 0.1 \\
\hline CC8 & 3.5 & 3.5 & 4 & 3.5 & 3 \\
\hline CC9 & 1.5 & 1.5 & 2 & 1.5 & 1.2 \\
\hline
\end{tabular}

The results of simulations with PTV driving behaviours were compared with simulation results of the AVs of this study. It should be note that the results from the simulation of TVs were considered as the reference category, and the rest of the simulation results were compared with them. These results are shown in Figure 14.

The results in Figure 14 show that AVs with All-Knowing driving behaviours improved the quality of traffic by $73 \%$, which is slightly more [by 6\%] than what the AVs of the current study obtained. Also, AVs with Normal driving behaviours defined by PTV (PTV, AV-Normal) achieved a 69\% overall improvement compared with TVs, which is so close to the results of this study. Additionally, the investigation of PTV's Cautious driving behaviours for AVs revealed that Cautious driving behaviours reduce traffic quality.

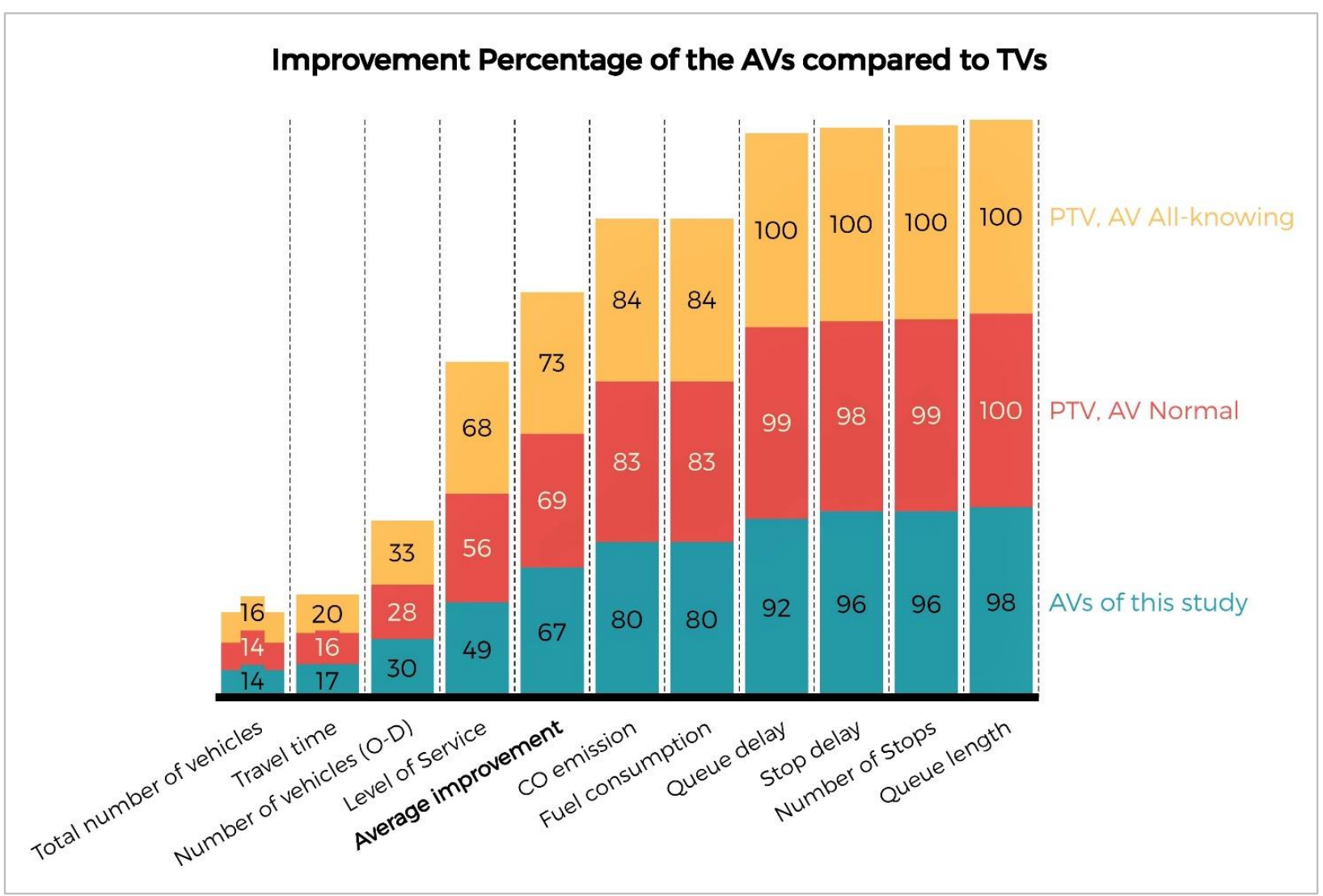

Figure 14. Improvement percentage of the AVs of this study versus PTV-AVs

In general, the comparison of results from the simulation of various driving behaviours of AVs defined by PTV indicates that there is only a $4 \%$ difference in the overall average improvement achieved by AVs with Normal driving behaviours compared to AVs with All-Knowing driving behaviours (both defined by PTV). 
driving behaviours would be representative of the other one with some margin of error. Moreover, the comparison of AV simulation results of this study to those of PTV validates the optimisation and simulation of this study. The optimised driving behaviours of this study obtained an overall improvement of $67 \%$, which is in line with the simulation result improvements shown by the PTV's Normal driving behaviours (69\%) and All-Knowing driving behaviours (73\%), with negligible variations of $2 \%$ and $6 \%$, respectively.

Following the comparison of the AVs of this study and those of the PTV, the shared traffic with PTV values were simulated. In this context, a day with normal traffic hours within the month with normal traffic condition ( $25^{\text {th }}$ of September) was chosen for simulation. The driving behaviour selected for this analysis was PTV's Normal driving behaviour (AV-Normal), as it had provided efficiency similar to that of the AVs of this study. Similar to what has previously been explained for the evaluation of the scenario improvement, TVs were considered as the reference category, and the simulation results of the shared scenarios were compared to those of TVs. As shown in Figure 15, the number of stops, queue length, and delay showed the largest reductions of all evaluated characteristics in this assessment, similar to the reductions previously found for the shared traffic of the current study. Also, the evaluation in this Section represented an average improvement of $73.6 \%$ when AVs represented $100 \%$ of the road traffic, an improvement average close to that of this study $(69.8 \%)$. Moreover, there was no substantial improvement in the quality of traffic once the percentage of AVs rose above $60 \%$. Such a result has already been found in the simulation results of the shared traffic of the current study.

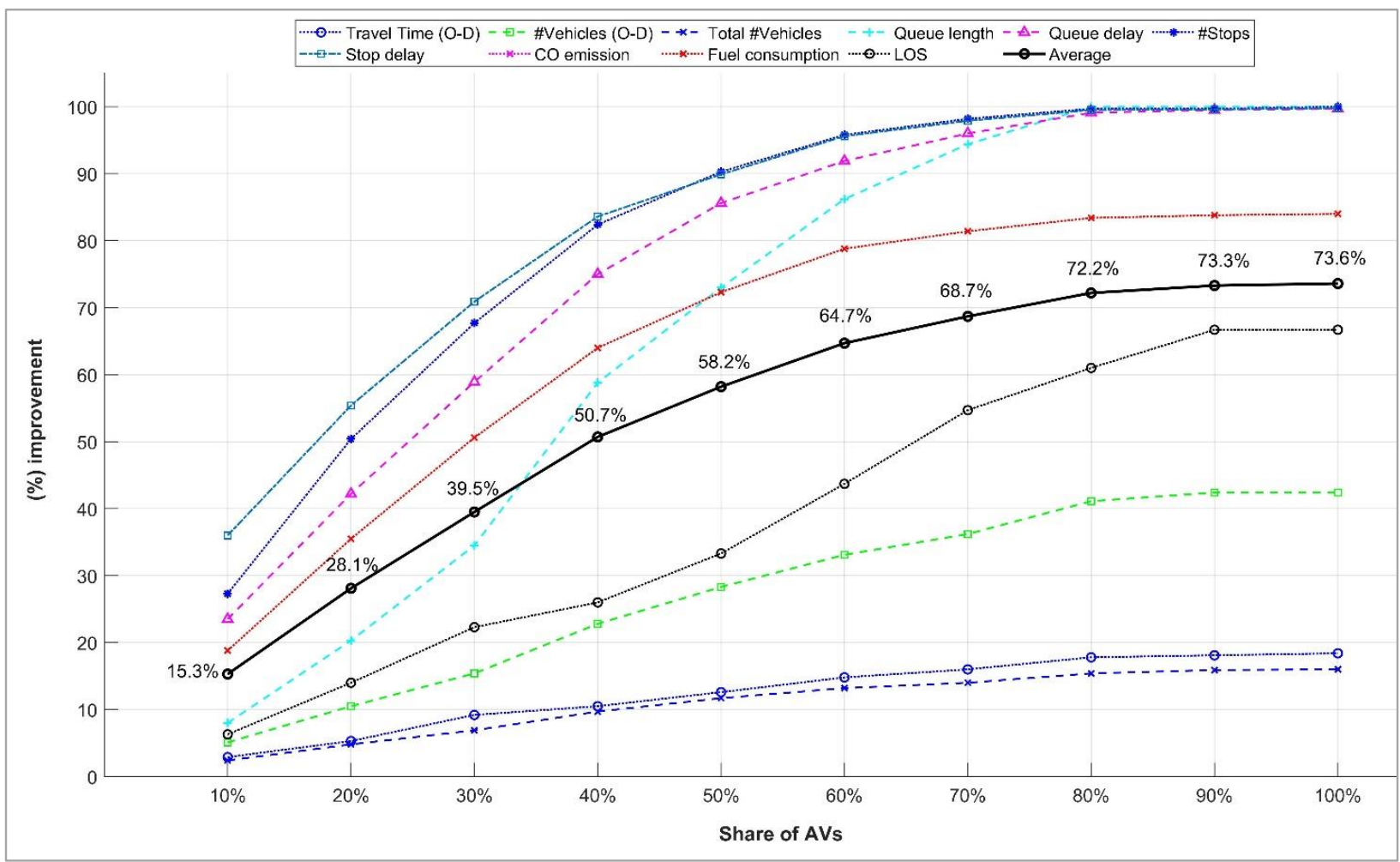

Figure 15. Improvement percentage of the shared traffic of PTV with Normal driving behaviours compared to traditional road network traffic

\section{Conclusions and Discussion}

The investigation into the optimisation of driving behaviours revealed that $\mathrm{CC} 0, \mathrm{CC} 1$, and $\mathrm{CC} 2$, when they are regarded as $0.38,0.45$, and 2 , respectively, can provide the greatest overall improvement in the quality of traffic. Changes of $\mathrm{CC} 3-\mathrm{CC} 9$ were not found to improve on the optimised scenario associated with $\mathrm{CC} 0, \mathrm{CC} 1$, and $\mathrm{CC} 2$; most had deleterious effects. Optimisation results indicated that, except for $\mathrm{CC} 0, \mathrm{CC} 1, \mathrm{CC} 2$, the rest of the Wiedemann parameters evaluated in this study should not be changed.

The assessment of the impacts of $\mathrm{CC} 0, \mathrm{CC} 1$, and $\mathrm{CC} 2$ on the characteristics evaluated in this study revealed that $\mathrm{CC} 1$ with $75 \%$ reduction ( 0.23 ) from its initial value (0.9) had the greatest impact (of all factorial changes) on the quality of traffic. Overall, $\mathrm{CC} 1(0.23)$ had the greatest impact on reducing travel time, queue length, and LOS, and on increasing the number of vehicles. Results showed that CC2 had the second-greatest effect 
on the quality of traffic (after CC1) when it was decreased by $75 \%$ (1) from its initial value (4). CC2 with a value of 1 had the most substantial impact among all factors on the reduction of queue delay, the number of stops, stop delay, fuel consumption, and $\mathrm{CO}$ emissions.

The simulation of TVs and AVs in various traffic hours throughout the year revealed that AVs obtained the greatest numerical improvement under normal traffic hours. However, looking at the simulation results in terms of the magnitude of the traffic flow in the peak traffic condition, AVs provided much more improvement in the quality of traffic in peak conditions than the normal and off-peak traffic conditions, especially in queue length and queue delay. In general, AVs showed higher efficiency in reducing the number of stops, stop delay, queue length, and queue delay, which could be due to their near-constant velocity and the low variation in their acceleration and decelerations.

Results related to the shared traffic simulations revealed that the number of stops, queue length, and delay were substantially decreased when the road was entirely populated by AVs. Such substantial reductions indicate that AVs might be more efficient when they represent a large share of the traffic. However, the results related to peak traffic hours in this context revealed that there was not a substantial improvement in the quality of traffic after AV share rose above $60 \%$. Therefore, dedicating $100 \%$ of the road traffic to AVs or devoting a dedicated lane for AVs in peak traffic hours might be as efficient as a shared road with $60 \% \mathrm{AVs}$. The simulation results of the shared road in the normal and off-peak traffic hours confirm such a declaration. According to the results in this context, there is an insignificant improvement in the overall results after a $60 \%$ share of AVs is reached in normal traffic hours and a $30 \%$ share for off-peak traffic hours.

The investigation of PTV driving behaviours for AVs revealed that there is only a $4 \%$ difference in the overall average improvement achieved by AVs with Normal driving behaviours compared to AVs with All-Knowing driving behaviours (both defined by PTV). Such a difference is negligible given the stochastic nature of the simulations. Therefore, one of those sets of driving behaviours, preferably AVs with Normal driving behaviours, would be representative of the other one with some margin of errors. Furthermore, the comparison of results from the simulation of the AVs of this study and those of PTV validated the simulation of this study. The simulation of AVs using the optimised driving behaviours of this study obtained an overall improvement of $67 \%$ in traffic quality, which is in line with simulated $69 \%$ improvement from the PTV's AV-Normal driving behaviours. The PTV All-Knowing driving behaviours resulted in an overall improvement of $73 \%$ in the quality of traffic, which is also close to the overall improvement obtained by the AVs of the current study, representing another validation for the simulation of the current study. Moreover, the comparison of the simulation results of the AVs of this study and those of PTV also validates the optimisation of the current study. It is worth highlighting that the optimisation of the current study revealed that only the three parameters of $\mathrm{CC} 0, \mathrm{CC} 1$, and $\mathrm{CC} 2$ have to be changed, and a change of value for the rest of the parameters does not improve the quality of traffic. The simulation results in this study validate such a declaration for the current study, as PTV AVs (with regard to change of all CC-parameters) represented almost similar improvement to those of this study. Moreover, the simulation of the shared road of PTV returned results similar to those of this study. The shared scenarios showed no substantial improvement in the quality of traffic once the AV share of the road rose above $60 \%$. Such a result has already been seen in the simulation results of the shared road of the current study.

In general, the simulation results in this study indicated that AVs could substantially improve the quality of traffic, and this improvement should increase with an increase in the share of AVs, up to a specific level, on the road. Therefore, the optimum percentage of AVs on the road varies based on the traffic conditions.

\section{Research Limitations}

While efforts were made to simulate AVs in the best way possible, and considering that the results of evaluations validated the employed research methodology of this paper, the findings of this research have to be considered in light of some limitations, as follows:

- The lack of sufficient traffic data at nodes and making assumptions regarding the traffic volumes. The lack of traffic data for the turning ratios at the motorway junctions and making assumptions in this regard made the simulation model, a conceptual model of the M50 motorway, and not an exact model, which was a major limitation in this research. This lack of data required the current study to make some assumptions regarding the input traffic volumes and keeping all cars in the model rather than making broader assumptions in this regard. This impacted the conformity of the simulation results with actual traffic running on the motorway. Also, the lack of 'observed' data prevented the study from running a comprehensive calibration and validation using GEH statistics which was another major limitation of this study. 


\section{Directions for Future Studies}

With regard to the results of this study and its limitations, future studies are recommended to consider the following items to improve the quality of their research, which also help fill the gaps of the current research in the field:

- Future studies are recommended to install their own digital counters at links and junctions to obtain accurate traffic data for the main links and each approaches of the junctions. This could be utilised using automatic traffic counters such as $\mathrm{JTC}^{1}$ (for junctions), and $\mathrm{ATC}^{2}$ (for the main links). Also, $\mathrm{ANPR}^{3}$ counters could be very useful to obtain accurate travel times throughout O-D pairs of their study. In this way, they would be able to capture the full impact of the traffic stream at junctions, main links, and vehicle's travel time and use those data for a comprehensive model calibration, which can be representative of all traffic parameters (travel time, traffic volume, queue length, delay time, and LOS).

- The current study made a comprehensive assessment of various traffic conditions of the year 2017. As a result, and due to the high number of the simulation scenarios and extensive simulation time, the researchers of this study could not focus on other road trip characteristics, such as the road accidents. In this context, future studies are recommended to integrate the effects of accidents on the highway simulation models and investigate how much those accidents impact travel time, queue length, delays, and the number of stops for TVs, which are the basis of assessments. Studies can model those accidents when simulating AVs to investigate how AVs might react to such incidents on the road and to what extent AVs can neutralise their impact on travel time, queues, and other evaluated parameters under a shared road traffic.

- Future studies are also recommended to investigate the application of AVs in urban traffic, such as their impact in coordinated signalised intersections. AVs' performance in roundabouts could also be evaluated to determine how AVs interact and communicate with other AVs and TVs to make the best decisions for yielding way or advancing in roundabout. Teixeira et al (2020) demonstrate the theoretical ability in this area and show how feasible this will be in the future. Such a scenario could

\footnotetext{
1 Junction Traffic Count

${ }^{2}$ Automatic Traffic Count

${ }^{3}$ Automatic number-plate recognition
} 
also be applied to AVs at an intersection, with results being compared with the results related to the roundabout scenario. In this way, AVs could be investigated for whether they operate more efficiently in roundabouts or intersections. Such an evaluation could address the best application of AVs at junctions with several approaches.

- The simulation results related to the operation of AVs in the off-peak traffic condition revealed that AVs might not be efficient after $30 \%$ penetration on the road; even they might have adverse implications such as an increase in travel time. The authors of the current study believe that increasing the speed limit of AVs might provide AVs with the opportunity of making more use of the capacity in free-flow traffic condition. Therefore, future studies are recommended to further the investigation in this context and simulate AVs with a higher speed limit in shared traffic with TVs.

\section{References}

Aghabayk, K., Sarvi, M., Young, W., \& Kautzsch, L. (2013). A Novel Methodology for Evolutionary Calibration of Vissim by Multi-threading. The $36^{\text {th }}$ Australasian Transport Research Forum (ATRF). Brisbane, Queensland, Australia.

Alam, Md.J., \& Habib, M.A. (2018). Investigation of the Impacts of Shared Autonomous Vehicle Operation in Halifax, Canada Using a Dynamic Traffic Microsimulation Model. Procedia Computer Science, 130, 496-503.

Bansal, P., Kockelman, K.M., \& Singh, A. (2016). Assessing public opinions of and interest in new vehicle technologies: An Austin perspective. Transportation Research Part C: Emerging Technologies, 67, 1-14.

Bartolini, C., Tettamanti, T., \& Varga, I. (2017). Critical Features of Autonomous Road Transport from the Perspective of Technological Regulation and Law. Transportation Research Procedia, 27, 791-798.

Bhargava, K., Choy, K.W., Jennings, P.A., Birrell, S.A., Higgins, M.D. (2020) Traffic simulation of connected and autonomous freight vehicles (CAV-F) using data-driven traffic model of a real-world road tunnel, Transportation Engineering, Vol 2, Article 100011

Bischoff, J., \& Maciejewski, M. (2016). Simulation of City-wide Replacement of Private Cars with Autonomous Taxis in Berlin. Procedia Computer Science, 83, 237-244.

Byrne, M.D. (2013). How Many Times Should a Stochastic Model Be Run? An Approach Based on Confidence Intervals. Semantic Scholar.

Byungkyu, B.P., \& Won, J. (2006). Microscopic Simulation Model Calibration and Validation Handbook. Virginia Transportation Research Council. Report No.: FHWA/VTRC 07-CR6.

Calvert, S.C., Kulnder, G., Steendijk, J.L.L., Snelder, M. (2020) The impact and potential of cooperative and automated driving from intelligent traffic signal corridors: Afield-
experiment. Case Studies on Transport Policy, Vol 8, pp 901-919

Casley, S.V., Jardim, A.S., \& Quartulli, A.M. (2013). A Study of Public Acceptance of Autonomous Cars. BSc Thesis. Computer Science Department, Worcester Polytechnic Institute.

Chu, L., Liu, H., Oh, J., \& Recker, W. (2003). A Calibration Procedure for Microscopic Traffic Simulation. IEEE International Conference on Intelligent Transportation Systems, ITSC 2003, 2, 1574-1579.

Dimitrakopoulos, G., Kavakli, Loucopoulos, P., Anagnostopoulos, D., \& Zographos, T. (2019). A Capabilityoriented Modelling and Simulation Approach for Autonomous Vehicle Management. Simulation Modelling Practice and Theory, 91, 28-47.

Durrani, U., Lee, C. \&, Zhao, P. (2016). Understanding the Differences in Lane Change Maneuvers of Cars and Heavy Vehicles on Freeways. Canadian Transportation Research Forum 51 st Annual Conference.

Essa, M. (2015). Calibration and Validation of Traffic Micro-Simulation Models for Safety Evaluation Using Automated Video-Based Conflict Analysis. MSc Thesis, The University of British Columbia, Vancouver, Canada.

Fagnant, D.J., \& Kockelman, K. (2015). Preparing a Nation for Autonomous Vehicles: Opportunities, Barriers and Policy Recommendations. Transportation Research Part A: Policy and Practice, 77, 167181.

Gao. Y. (2008). Calibration and Comparison of the Vissim and INTEGRATION Microscopic Traffic Simulation Models. MSc Thesis. Virginia Polytechnic Institute and State University.

Gora, P., Katrakazas, C., Drabicki, A., Islam, F., Piotr, O. (2020) Microscopic traffic simulation models for connected and automated vehicles (CAVs) - state-of-the-art, Procedia Computer Science, Vol 170, pp 474-481

Gardes, Y., May, A., Dahlgren, J., \& Skabardonis, A. (2002). Freeway Calibration and Applications of the Paramics Model. The 81st Annual Meeting on Transportation Research Board, Washington, D.C., USA. 
Ge, Q., \& Menendez, M. (2014). An Efficient Sensitivity Analysis Approach for Computationally Expensive Microscopic Traffic Simulation Models. Transportation Research Board: International Journal of Transportation, 2(2), 49-64.

Gerado, C.G.J., Jesus, A.L., \& Ricardo, O.M. (2015). Modelling the Turning Speed and Car Following Behaviors of Autonomous Vehicles in a Virtual World. Ingenieria, 16(3), 391-405.

Hancock, P.A., Nourbakhsh, I., \& Stewart, J. (2019). On the Future of Transportation in an Era of Automated and Autonomous Vehicles. Proceedings of the National Academy of Sciences, 116 (16), 7684-7691.

Hawkins, A.J. (2018). Inside Waymo's Strategy to Grow the Best Brains For Self-Driving Cars. THE VERGE. Retrieved from https://www.theverge.com/2018/5/9/17307156/google-waymo-driverless-carsdeep-learning-neural-net-interview.

Heale, R., \& Twycross, A. (2015). Validity and Reliability in Quantitative Studies. BMJ Journal.

Higgs, B., Abbas, M.M., \& Medina, A. (2011). Analysis of the Wiedemann Car Following Model over Different Speeds using Naturalistic Data. The $3^{\text {rd }}$ International Conference on Road Safety and Simulation. Procedia of RSS Conference.

Howard, D., \& Dai, D. (2014). Public Perceptions of Self-Driving Cars: The Case of Berkeley, California. Transportation Research Board, 93rd Annual Meeting.

Jones, S.L., Sullivan, A., Anderson, M., Malave, D., \& Cheekoti, N. (2004). Traffic Simulation Software Comparison Study. Department of Civil \& Environmental Engineering. The University of Alabama at Birmingham. Report No.: FHWA/CA/OR.

\section{Katrakazas, C., Quddus, M., Chen, W-H. (2019) A new integrated collision risk assessment methodology for} autonomous vehicles, Accident Analysis \& Prevention, Vol 127, pp 61-79

Krueger, R., Rashidi, T.H., \& Rose, J.M. (2016). Preferences for Shared Autonomous Vehicles. Transportation Research Part C: Emerging Technologies, 69, 343-355.

Kyriakidis, M., Happee, R., \& De-Winter, J.C.F. (2015). Public Opinion on Automated Driving: Results of an International Questionnaire among 5000 Respondents. Transportation Research Part F: Traffic Psychology and Behaviour, 32, 127-140.

Laan, Z.V., \& Sadabadi, K.F. (2017). Operational Performance of a Congested Corridor With Lanes Dedicated to Autonomous Vehicle Traffic. International Journal of Transportation Science and Technology, 6, 42-52.

Litman, T. (2016). Autonomous Vehicle Implementation Predictions. Victoria Transport Policy Institute. Retrieved from: http:/www.vtpi.org/documents/evaluation.php.

Liu, B., Shi, Q., Song, Z., \& Kamel, A. E. (2019). Trajectory Planning for Autonomous Intersection Management of Connected Vehicles. Simulation Modelling Practice and Theory, 90, 16-30.

Lowens E. N., \& Machemehl B. R. (2007). Sensitivity of Simulated Capacity to Modification of Vissim Driver Behavior Parameters. Transportation Research Record: Journal of the Transportation Research Board.

Lu, Z., Fu, T., Fu, L., Shirvani, S., \& Jiang, C. (2016). A Video-Based Approach to Calibrating CarFollowing Parameters in Vissim for Urban Traffic. International Journal of Transportation Science and Technology, 5(1), 1-9.

Ma, T., \& Abdullhai, B. (2002). Genetic Algorithm-Based Optimisation Approach and Generic Tool for Calibrating Traffic Microscopic Simulation Parameters. Transportation Research Record: Journal of the Transportation Research Board, 1800(1), 6-15.

Menneni, S, Sun, C, \& Vortisch, P. (2008). Micro-Simulation Calibration Using Speed-Flow Relationships. Transportation Research Record: Transportation Research Board, 2088(1), 1-14.

NHTSA. (2015). Distracted Driving. National Highway Traffic Safety Administration, the US Department of Transportation. Retrieved from https://www.nhtsa.gov/risky-driving/distracted-driving.

NHTSA. (2015). Motor Vehicle Crashes - Report DOT HS 812 318. National Highway Traffic Safety Administration, the US Department of Transportation. Retrieved from https://crashstats.nhtsa.dot.gov/Api/Public/ViewPublication/812318

NHTSA. (2019). Automated Vehicles for Safety. National Highway Traffic Safety Administration, the US Department of Transportation. Retrieved from https://www.nhtsa.gov/technologyinnovation/automated-vehicles-safety

Park, B., \& Qi, H. (2005). Development and Evaluation of a Procedure for the Calibration of Simulation Models. Transportation Research Record: Journal of the Transportation Research Board, 1934, 208-217.

Park, B., \& Schneeberger, J. (2003). Microscopic Simulation Model Calibration and validation: a case study of the Vissim simulation model for a coordinated actuated Signal system. Transportation Research Record: Journal of the Transportation Research Board, 1856(1), 185-192. 
PennDOT. (2016). Pennsylvania Takes Steps to Lead on Autonomous Vehicle Development, Testing with Newly Established Task Force, Legislation. Pennsylvania Department of Transportation (PennDOT). Retrieved from: http://www.penndot.gov/Pages/all-news-details.aspx?newsid=233\#.V1COyNkrKU1 PTV Group. (2017). Vissim Manual. Microscopic Multi-modal Traffic Flow Simulation Software Package. PTV Planung Transport Verkehr AG.

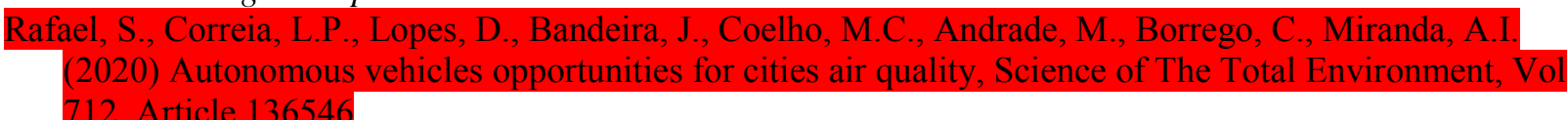

Ronaldo, A. (2012). Comparison of the Micro-Simulation Software Aimsun \& Ihcm-1997 for Highway Traffic Performance Analysis. Ministry of Transportation Republic of Indonesia - Civil Engineering Forum. XXI/3.

RSA (2017). Accident Database. Road Safety Authority of Ireland. Retrieved from: https://www.rsa.ie/RSA/Road-Safety/RSA-Statistics/Collision-Statistics/Ireland-Road-Collisions/.

Russo, C. (2008). The Calibration and Verification of Simulation Models for Toll Plazas. MSc Thesis. The University of Central Florida.

SAE. (2016). Taxonomy and Definitions for Terms Related to Driving Automation Systems for On-Road Motor Vehicles. Society of Automotive Engineers. Report J3016_201609. Retrieved from https://www.sae.org/standards/content/j3016 201609/.

Saidallah, M., El-Fergougui, A., Elalaoui, A.E. (2016). A Comparative Study of Urban Road Traffic Simulators. The $5^{\text {th }}$ International Conference on Transportation and Traffic Engineering (ICTTE 2016). 81 .

Schoettle, B., \& Sivak, M. (2014b). A survey of Public Opinion about Autonomous and Self-Driving Vehicles in the U.S., the U.K., and Australia. University of Michigan, Ann Arbor, Transportation Research Institute, UMTRI-2014-21.

Schoettle, B., \& Sivak, M. (2014c). Public Opinion about Self-Driving Vehicles in China, India, Japan, the U.S., the U.K., and Australia, Michigan, USA. University of Michigan, Ann Arbor, Transportation Research Institute, UMTRI-2014-30.

Siswaningsih, W., Firman, H., Zackiyah, \& Khoirunnisa, A. (2017). Development of Two-Tier Diagnostic Test Pictorial-Based for Identifying High School Students Misconceptions on the Mole Concept. Journal of Physics: Conf. Series 812 (2017) 012117, 1-7.

Song, G., Yu, L., \& Geng, Z. (2015). Optimization of Wiedemann and Fritzsche Car-following Models for Emission Estimation. Transportation Research Part D: Transport and Environment, 34, 318-329.

Taber, K.S. (2018). The Use of Cronbach's Alpha When Developing and Reporting Research Instruments in Science Education. Springer Netherlands, 48, 6, 1273-1296.

Talebpour, A., \& Mahmassani, H.S. (2016). Influence of Connected and Autonomous Vehicles on Traffic Flow Stability and Throughput. Transportation Research Part C: Emerging Technologies, 71, 143-163.

Tavakol, M., \& Dennick, R. (2011). Making Sense of Cronbach's Alpha. International Journal of Medical Education, 2, 53-55.

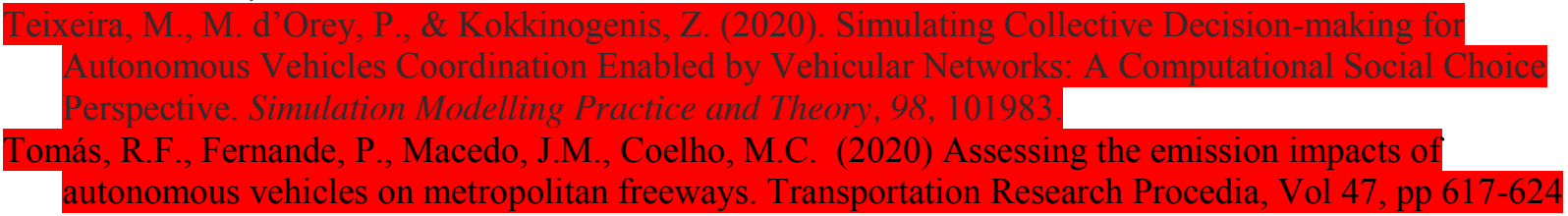

TII. (2017). TII Traffic Data Site. Transport Infrastructure Ireland.

Trucano, T.G., Swiler, L.P., Igusa, T., \& Oberkampf, W.L., \& Pilch, M. (2006). Calibration, Validation, and Sensitivity Analysis: What's what? Reliability Engineering \& System Safety, 91. 1331-1357.

Underwood, S. (2014). Automated Vehicles Forecast: Expert Forecast and Roadmap for Sustainable Transportation - Automated, Connected, and Electric Vehicle Systems. Vehicle Symposium Opinion Survey. Institute for Advanced Vehicle Systems, University of Michigan - Dearborn.

Virdi, N., Grzybowska, H., Waller, S.T., Dixit, V. (2019). A safety assessment of mixed fleets with Connected and Autonomous Vehicles using the Surrogate Safety Assessment Module. Accident Analysis and Prevention, 131, 95-111.

Wisconsin DOT (2018). Vissim Calibration Settings. Wisconsin Department of Transportation. Last Updated: May $31^{\text {st }}, 2018$.

Woody, T. (2006). Calibrating Freeway Simulation Models in Vissim. MSc Thesis. The University of Washington. 
1017

1018

1019

1020

1021

1022

1023

1024

1025

1026

1027

1028

1029

1030

1031

Yea, L., \& Yamamoto, T. (2018). Modelling Connected and Autonomous Vehicles in Heterogeneous Traffic Flow. Physica A: Statistical Mechanics and its Applications, 490, 269-277.

Zaiontz, C. (2019). Cronbach's Alpha. Real Statistics Using Excel. Retrieved from http://www.realstatistics.com/reliability/cronbachs-alpha/.

Zeidler, V., Buck, S., Kautzsch, L., Vortisch, P. \& Weyland, C. (2019). Simulation of Autonomous Vehicles Based on Wiedemann's Car Following Model in PTV Vissim. Transport Research Board, TRB annual meeting online, 2019.

Zheng, S., Li, H., Huang, Z., Li, K., Qin, L. Flow-balanced-based collaborative strategies and simulation of vehicle group behaviors for on-ramp areas. Simulation Modelling Practice and Theory, 2020, Vol 103, Article 10209

Zhichu, C. (1989). Allowable Limit of Error in Clinical Chemistry Quality Control. Scientific Notes. Retrieved from http://clinchem.aaccjnls.org/content/clinchem/35/4/630.full.pdf.

Zhu, F., \& Ukkusuri, S. (2018). Modelling the Proactive Driving Behaviour of Connected Vehicles: A CellBased Simulation Approach. Computer-Aided Civil and Infrastructure Engineering, 33, 262-281. 